NBER WORKING PAPER SERIES

\title{
EXPORTS AND CREDIT CONSTRAINTS UNDER INCOMPLETE INFORMATION: THEORY AND EVIDENCE FROM CHINA
}

\author{
Robert C. Feenstra \\ Zhiyuan Li \\ Miaojie Yu \\ Working Paper 16940 \\ http://www.nber.org/papers/w16940
NATIONAL BUREAU OF ECONOMIC RESEARCH
1050 Massachusetts Avenue
Cambridge, MA 02138
April 2011

We thank Kyle Bagwell, Kalina Monova, Larry Qiu, and seminar participants at the NBER, Harvard, and University of Victoria for their helpful comments and suggestions. Financial support from the National Science Foundation is gratefully acknowledged. The views expressed herein are those of the authors and do not necessarily reflect the views of the National Bureau of Economic Research.

NBER working papers are circulated for discussion and comment purposes. They have not been peerreviewed or been subject to the review by the NBER Board of Directors that accompanies official NBER publications.

(C) 2011 by Robert C. Feenstra, Zhiyuan Li, and Miaojie Yu. All rights reserved. Short sections of text, not to exceed two paragraphs, may be quoted without explicit permission provided that full credit, including $(\odot)$ notice, is given to the source. 
Exports and Credit Constraints Under Incomplete Information: Theory and Evidence from

China

Robert C. Feenstra, Zhiyuan Li, and Miaojie Yu

NBER Working Paper No. 16940

April 2011

JEL No. D8,F1,G2

\begin{abstract}
This paper examines why credit constraints for domestic and exporting firms arise in a setting where banks do not observe firms' productivities. To maintain incentive-compatibility, banks lend below the amount needed for first-best production. The longer time needed for export shipments induces a tighter credit constraint on exporters than on purely domestic firms, even in the exporters' home market. Greater risk faced by exporters also affects the credit extended by banks. Extra fixed costs reduce exports on the extensive margin, but can be offset by collateral held by exporting firms. The empirical application to Chinese firms strongly supports these theoretical results, and we find a sizable impact of the financial crisis in reducing exports.
\end{abstract}

Robert C. Feenstra

Department of Economics

University of California, Davis

One Shields Avenue

Davis, CA 95616

and NBER

rcfeenstra@ucdavis.edu

Zhiyuan Li

School of Economics

Shanghai University of Finance \& Economics

777 Guoding Road, Shanghai, P.R. China. 200433

zhyli97@gmail.com
Miaojie Yu

China Center for Economic Research

Peking University

Beijing, China

mjyu@ccer.edu.cn 


\section{Introduction}

The financial crisis of 2008 has led researchers to ask whether credit constraints faced by exporters played a significant role in the fall in world trade. There are a wide range of answers: Amiti and Weinstein (2009) argue that trade finance was important in the earlier Japanese financial crisis of the 1990s, and Chor and Manova (2010) find that financially vulnerable sectors in source countries did indeed experience a sharper drop in monthly export to the United States. In contrast, Levchenko, Lewis and Tesar (2010) find no evidence that trade credit played a role in restricting imports or exports for the recent episode in the U.S., while for Belgium, Behrens, Corcos and Mion (2010) argue that to the extent that financial variables impacted exports, they also impacted domestic sales to the same extent. Of course, the potential causal link between financial development and international trade at country level was recognized long before the recent crisis. For example, Kletzer and Bardhan (1987; see also Qiu, 1999, Beck, 2002, and Matsuyama, 2005) argued that credit-market imperfections would adversely affect exporters needing more finance and hence influence trade patterns. That theme was picked up in a Melitz (2003) model by Chaney (2005), and implemented by Manova (2008), who argue that credit constraints affect exporting firms in different countries and industries differently due to fixed costs. ${ }^{1}$

In view of these divergent empirical findings, we believe that it is useful to go back to the theory and ask why credit for exports should be allocated any differently than credit for domestic sales. Amiti and Weinstein (2009) argue forcefully for two reasons: there is a longer time-lag between production and the receipt of sales revenue; and exporters also face inherently more risk, since it is more difficult to enforce payment across country boundaries. They define "trade finance" (as distinct from "trade credit") to be the financial contracts that arise to offset these risks for exporters. $^{2}$ To these reasons we add the extra fixed costs faced by exporters, in a Melitz-style model, as a third reason why exporters might need more credit. The goal of this paper is to build these three reasons into a model of heterogeneous firms obtaining working-capital loans from a bank, to see whether exports are indeed treated differently from domestic sales in theory. We test the predictions of the model using firm-level data for China.

The key feature of our model is that the bank has incomplete knowledge of firms, in two respects.

\footnotetext{
${ }^{1}$ Other papers dealing with trade and finance include Qiu (1999), Greenaway, et al (2007), Muûls (2008), Buch, et al (2008), Héricourt and Poncet (2009), Poncet et al (2009), and Egger and Keuschnigg (2011).

${ }^{2}$ Trade credit refers to an accounting convention whereby accounts receivable for either domestic or foreign sales are credited when a shipment takes place and before payment is received.
} 
First, the bank cannot observe the productivity of firms. We believe this assumption is realistic in rapidly growing economies such as China with rapid entry, and perhaps more generally. The bank will confront firms with a schedule specifying the amount of the loan and the interest payments to maximize its own profits. From the revelation principle, without loss of generality we can restrict attention to schedules that induce firms to truthfully reveal their productivity. Second, the bank cannot verify whether the loan is used to cover the costs of production for domestic sales or for exports. This second assumption means that we are not really modeling the loans from the bank as "trade finance": such loans would typically specify the names of the buying and selling party, at least, so the bank could presumably verify whether the loan was for exports or not. Rather, the loans being made by the bank are for "working capital," to cover the costs of current production, regardless of where the output is sold. The assumption that banks cannot follow a loan once the money enters the firm is made in a different context by Bolton and Scharfstein (1990), for example.

With these assumptions, in section 2 we derive the incentive-compatible loan schedule by the bank that maximizes its own profits. Sales revenue of firms is less than would occur in the absence of any working-capital needs, i.e. the incentive-compatible loans impose credit constraints on firms. The reason for these credit constraints is that a firm suffers only a second-order loss in profits from producing slightly less than the first-best and borrowing less from the bank, but obtains a first-order gain from reducing its interest payments in this way. So a firm that is not credit constrained will never reveal its true productivity and borrow enough to produce at the first-best; hence, incentive-compatibility requires that the firm is credit constrained. Furthermore, because banks cannot follow a loan once it enters the firm, the credit constraint applies to the exports and domestic sales of a firm engaged in both these activities - which we refer to as an exporting firm. Because exports take longer in shipment, such exporting firms face a tighter credit constraint on both markets than purely domestic firms

So our answer to the question "is credit for exports and domestic sales treated differently?" is nuanced: when these activities occur in the same firm, the bank treats them equally; but when these activities occur in an exporting firm and a purely domestic firm respectively, they are indeed treated differently. The tighter credit constraint on exporting firms comes from the first reason for exports to be treated differently than domestic sales - the longer time-lag between production and receipt of sales revenue - and reduces exports on the intensive and extensive margins. The second reason, greater risk, arises due to the risk of a firm not being paid - what we call "project risk" - 
or the default risk of the firm not repaying the bank. We find that higher default risk for exporters raises their interest payments for any given loan, acting in a similar manner to credit constraints. The third reason, which is the extra fixed costs faced by exporters, reduces the extensive margin of exports. As in Manova (2008), we find that higher expected collateral held by exporters can offset this effect and expand the extensive margin.

These theoretical results are tested using a rich panel dataset of Chinese manufacturing firms over the period of 2000-2008, in sections 3 and 4. This application is of special interest because China's exports experienced unprecedented growth over the past decades, while it is believed that Chinese firms faced severe credit constraints: according to the Investment Climate Assessment surveys in 2002, China was among the group of countries that had the worst financing obstacles (Claessens and Tzioumis, 2006). Using China's firm-level data to test our model, we estimate a structural equation under which sales revenue is a linear function of interest payments and other variables. The coefficients in this regression can differ across firms, which we control for using the fixed effects-instrumental variable technique of Murtazashvili and Wooldridge (2008). We obtain robust empirical evidence that exporting firms face more severe credit constraints than purely domestic firms, and find that the financial crisis further tightened this credit constraint. We also confirm the empirical finding of Manova, Wei and Zhang (2009) that the credit constraint is much weaker for multinational firms in China. ${ }^{3}$ Conclusions and directions for further research are discussed in section 5 .

\section{Incentive-Compatible Loans}

\subsection{The Model}

We suppose there are two countries, home and foreign (henceforth foreign counterparts of the variables are denoted with an asterisk $*$ ). Labor is the only factor for production and the population is of size $L$ at home. There are two sectors, where the first produces a single homogeneous good that is freely traded and chosen as numeraire. Each unit of labor in this sector produces a given number of units of the homogeneous good. We assume that both countries produce in this sector and it follows that wages are thus fixed by the productivity in this sector. The second sector produces a continuum of differentiated goods under monopolistic competition, as in Melitz (2003).

\footnotetext{
${ }^{3}$ That result is found for other developing countries by Harrison and McMillan (2003) and Antràs, Desai and Foley (2009).
} 


\subsubsection{Consumers}

Consumers are endowed with one unit of labor and the preference over the differentiated good displays a constant elasticity of substitution. The utility function of the representative consumer is

$$
U=q_{0}^{1-\mu}\left(\int_{\omega \in \Omega} q(\omega)^{\frac{\sigma-1}{\sigma}} d \omega\right)^{\frac{\sigma}{\sigma-1} \mu}
$$

where $\omega$ denotes each variety, $\Omega$ is the set of varieties available to the consumer, $\sigma>1$ is the constant elasticity of substitution between each variety, and $\mu$ is the share of expenditure on the differentiated sector. The aggregate price index in the differentiated sector is:

$$
P=\left(\int_{\omega \in \Omega} p(\omega)^{1-\sigma} d \omega\right)^{\frac{1}{1-\sigma}}
$$

where $p(\omega)$ is the price of each variety. Accordingly, the demand for each variety is:

$$
q(\omega)=\frac{Y}{P}\left(\frac{p(\omega)}{P}\right)^{-\sigma}
$$

where $Y \equiv \mu w L$ is the total expenditure on the differentiated good at home.

\subsubsection{Firms and the Bank}

Firms in the differentiated sector need to borrow working capital to finance a fraction $\delta$ of their fixed and variable costs. The parameter $\delta$ could reflect the capital-intensity of production, for

example. We treat $\delta$ as equal across all domestic and exporting firms in the model, but in our empirical application will allow it to differ across firms and sectors in an idiosyncratic manner.

Firms borrow from a single, monopolistic bank, and the bank will charge interest payments to maximize its profits. The bank faces an opportunity cost of $i$ - the interest rate - on its loans. We will assume that the loans for domestic (export) projects are paid back after $\tau_{d}\left(\tau_{e}\right)$ periods, and further assume that $\tau_{e}>\tau_{d}$, reflecting the longer time-lags involving in the shipping of exports. So the opportunity cost to the bank for a loan extended for domestic or exports sales is $i \tau_{d}$ and $i \tau_{e}$, respectively.

We introduce project risk by supposing that there is some probability that any project (domestic or export) receives its sales revenue. Domestic sales are successful with probability $s_{d} \leq 1$, meaning that firms receive their revenue $p_{d} q_{d}$ with probability $s_{d}$, and zero otherwise. Likewise, exports are successful with probability $s_{e} \leq s_{d}$. The possibly lower probability of collecting on export sales can 
reflect more stringent specifications of quality in foreign countries, which the exporter might not achieve; the difficulty of taking legal action to collect payment across country boundaries; or any other risks associated with exports.

We also introduce default risk by supposing that the loan and interest payment might not be paid back by the firm. The probability that the domestic firm pays back the loan and interest payment is $\rho_{d}$, and that for the exporter is $\rho_{e}$. The default risk may due to the the project not being successful, or some other extra uncertainties that makes the firm to default the payment. Lack of financial contractibility and contract enforcement discussed by Manova (2008) is one possible source of these uncertainties. We assume that $\rho_{d} \leq s_{d}$ and $\rho_{e} \leq s_{e}$ to indicate these extra uncertainties of repayment, and further assume that $\rho_{e} \leq \rho_{d}{ }^{4}$

\subsection{Domestic Firms' Decision}

Under incomplete information, the bank does not observe the productivity level $x$ of a firm coming to it for a loan. In order to maximize profits, the bank will design a schedule of loans $M_{d}\left(x^{\prime}\right)$ and interest payments $I_{d}\left(x^{\prime}\right)$ contingent on the announced productivity level $x^{\prime}$. If the firm defaults, which occurs with probability $\left(1-\rho_{d}\right)$, we follow Manova (2008) in assuming that the bank can collect the collateral amount, $K_{d}$.

By the revelation principle, the bank can do no better than to design a loan-interest payment schedule that induces firms to reveal their true productivity, $x^{\prime}=x$. Adding this incentive compatibility condition as a constraint, the domestic firm's profit maximization problem is:

$$
\begin{aligned}
\max _{x^{\prime}, q_{d}} E\left(\pi_{d}\left(x, x^{\prime}\right)\right) & =s_{d} p_{d} q_{d}-(1-\delta)\left(\frac{q_{d} w}{x}+C_{d}\right)-\rho_{d}\left(M_{d}\left(x^{\prime}\right)+I_{d}\left(x^{\prime}\right)\right)-\left(1-\rho_{d}\right) K_{d} \\
\text { s.t. } & E\left(\pi_{d}(x, x)\right) \geq E\left(\pi_{d}\left(x, x^{\prime}\right)\right) \\
& E\left(\pi_{d}(x, x)\right) \geq 0 \\
& M_{d}\left(x^{\prime}\right) \geq \delta\left(\frac{q_{d} w}{x}+C_{d}\right),
\end{aligned}
$$

and also subject to the domestic demand function in (2). In this problem, the firm pays the fraction $(1-\delta)$ of costs with certainty, while borrowing for the remainder and repaying with probability $\rho_{d}$. The first constraint is the incentive compatibility constraint, the second ensures that expected profits are non-negative, and the third specifies that the amount of the loan must cover the fraction $\delta$ of fixed and variable costs at the chosen production level $q_{d}$. Manova (2008) includes another

\footnotetext{
${ }^{4}$ Note that Manova (2008) assumes $s_{d}=s_{e}=1$ and focuses on $\rho_{e}<1$. In contrast, Amiti and Weinstein (2009) discuss the reasons to have $s_{d}<s_{e}$, which they refer to as default risk but we call project risk.
} 
constraint, stating that when the firm pays back the loan and interest to the bank, the sum of those amounts cannot exceed the total revenue of the firm. This condition, which we call a "cash flow constraint," might or might not be binding at the optimal solution we derive in its absence. For convenience we ignore this constraint for now and introduce it in section 2.5.

The third constraint above will be binding in equilibrium, which implies: ${ }^{5}$

$$
q_{d}=\left(\frac{M_{d}\left(x^{\prime}\right)}{\delta}-C_{d}\right) \frac{x}{w}
$$

Provided that the loan and interest payment schedules are differentiable in $x^{\prime}$, then the incentivecompatibility condition implies that,

$$
\left.\frac{\partial E\left(\pi_{d}\left(x, x^{\prime}\right)\right)}{\partial x^{\prime}}\right|_{x^{\prime}=x}=0
$$

By substituting the quantity equation (4) into the demand function (2) we solve for the price. Using that we derive the firms' profits $E\left(\pi_{d}\left(x, x^{\prime}\right)\right)$, and take the derivative as in (5) to obtain:

$$
\left[\Phi_{d}\left(x, M_{d}(x)\right)+\delta\left(1-\rho_{d}\right)-1\right] \frac{M_{d}^{\prime}(x)}{\delta}=\rho_{d} I_{d}^{\prime}(x),
$$

where

$$
\begin{aligned}
\Phi_{d}\left(x, M_{d}(x)\right) & \equiv\left[s_{d} p_{d}\left(\frac{\sigma-1}{\sigma}\right)\right] / \frac{w}{x} \\
& =s_{d}\left(\frac{\sigma-1}{\sigma}\right)\left(\frac{M_{d}(x)}{\delta}-C_{d}\right)^{-\frac{1}{\sigma}}\left(\frac{x P}{w}\right)^{\frac{\sigma-1}{\sigma}} Y^{\frac{1}{\sigma}} .
\end{aligned}
$$

The value of $\Phi_{d}$ on the first line of (7) is recognized as the ratio of expected marginal revenue to marginal costs. A firm facing the project risk of $s_{d}$ but without any need to borrow will produce where $\Phi_{d}=1$, while a firm that produces less due to insufficient loans will have $\Phi_{d}>1$. This means that $\Phi_{d}$ is a measure of firm's credit constraint, and the larger is $\Phi_{d}$ then the lower is the quantity produced due to this constraint. The second line of (7) is obtained by using the quantity in (4) and solving for the corresponding price from demand (2). It is apparent that having lower loans $M_{d}(x)$ will raise $\Phi_{d}$, indicating that the credit constraint is tightened.

We can now develop some intuition as to why the bank might need to impose credit constraints. Let us suppose that the bank lends more to higher productivity firms, and also collects more in interest payments: we will confirm that these monotonicity conditions hold in the optimal schedules for the bank. Then in (6), both $M_{d}^{\prime}(x)$ and $I_{d}^{\prime}(x)$ are positive. It follows that the expression in

\footnotetext{
${ }^{5}$ Note that $q$ and $p$ both depend on $x$, but for simplicity we omit this from the notation.
} 
brackets on the left must be positive, so in the no-default case where $\rho_{d}=1$ it follows that the firm must be credit constrained, i.e. $\Phi_{d}>1$. The reason this condition is needed is that a firm that is producing at the first-best with marginal revenue equal to marginal cost would have only a second-order loss in profits from announcing a slightly smaller productivity $x^{\prime}$, and producing slightly less. But the firm would have a first-order gain from the reduction in interest payments $I_{d}^{\prime}(x)>0$. So a firm at the first-best would always understate its productivity, and it follows that a credit constraint is needed to ensure incentive compatibility. We will formalize this intuition below, and show that $\Phi_{d}>1$ even in the presence of default.

\subsection{Exporters' Decision}

We assume that the monopolistic bank cannot enforce different contracts to separate loans for domestic market and export market. Rather, exporters are free to determine how to allocate the loan to both markets. In comparison with purely domestic firms, exporters have three differences: (i) longer time needed to pay back their export loans $\tau_{e}>\tau_{d}$ (which enters the bank's problem analyzed in the next section); (ii) potentially greater project risk, $s_{e} \leq s_{d}$, and default risk, $\rho_{e} \leq \rho_{d}$, where we assume that the default risk for the exporter applies to the total loan from the bank; (iii) additional fixed costs of exporting, which are denoted by $C_{e}$.

An exporter chooses quantities to produce at domestic market and export market and claims a productivity $x^{\prime}$ to maximize its expected profit:

$$
\begin{aligned}
\max _{x^{\prime}, q_{d}, q_{e}} E\left(\pi_{e}\left(x, x^{\prime}\right)\right) & =s_{d} p_{d} q_{d}+s_{e} p_{e} q_{e}-(1-\delta)\left(\frac{q_{d} w}{x}+C_{d}+\frac{q_{e} w}{x}+C_{e}\right) \\
& -\rho_{e}\left(M_{e}\left(x^{\prime}\right)+I_{e}\left(x^{\prime}\right)\right)-\left(1-\rho_{e}\right) K_{e}, \\
\text { s.t. } & E\left(\pi_{e}(x, x)\right) \geq E\left(\pi_{e}\left(x, x^{\prime}\right)\right) \\
& E\left(\pi_{e}(x, x)\right) \geq E\left(\pi_{d}(x, x)\right) \\
& M_{e}\left(x^{\prime}\right) \geq \delta\left(\frac{q_{d} w}{x}+C_{d}+\frac{q_{e} w}{x}+C_{e}\right),
\end{aligned}
$$

and subject to export demand,

$$
q_{e}=\frac{Y^{*}}{P^{*}}\left(\frac{p_{e}}{P^{*}}\right)^{-\sigma}
$$

where $Y^{*}$ is the foreign total expenditure on the differentiated good. ${ }^{6}$ The total loan received by

\footnotetext{
${ }^{6}$ We do not make explicit the transportation costs to the export market for expositional convenience, but that iceberg cost can readily be incorporated into the definition of the "effective" foreign expenditure on the differentiated good $Y^{*}$. That is, including iceberg transport costs $\tau>1$ then export demand is $q_{e}=\left(\tilde{Y}^{*} / P^{*}\right)\left(\tau p_{e} / P^{*}\right)^{-\sigma}$, which equals that shown in (9) by defining $Y^{*}=\tilde{Y}^{*} \tau^{-\sigma}$.
} 
the exporter is denoted by $M_{e}$ and total interest payments are $I_{e}$, while $K_{e}$ is the exporter's total collateral.

The first two constraints above are analogous to those for the domestic firm, but the third constraint is different and important. It states that the total amount of the loan given to the exporter must cover the working-capital needs of both domestic and export production costs. From the exporting firm's perspective, these funds are fully fungible so the bank is making a single loan. Likewise, the bank will receive a single interest payment, which is $\rho_{e} I_{e}\left(x^{\prime}\right)$ in expected value. In addition, a "cash flow constraint" stating that the loan amount plus interest cannot exceed the available revenue from the firm, also applies for exporters. It might or might not be binding and we ignore this constraint for now.

Setting up a Lagrangian with the objective function and the third constraint, and solving this problem for the choice of $q_{d}$ and $q_{e}$, it is readily shown that the firm will maximize its profit by choosing quantities in the two markets such that:

$$
s_{d} p_{d}\left(\frac{\sigma-1}{\sigma}\right)=s_{e} p_{e}\left(\frac{\sigma-1}{\sigma}\right) .
$$

This condition states that the loan will be allocated within the firm so that expected marginal revenue in the domestic and export markets are equalized. It means that for any given loan, the bank will know exactly how production is allocated between the two markets. Thus for notational convenience, we break up the total loan $M_{e}\left(x^{\prime}\right)$ into the component intended to cover domestic costs $M_{e}^{d}\left(x^{\prime}\right)$, and the component intended to cover export costs $M_{e}^{e}\left(x^{\prime}\right)$. That is, for any announcement of productivity $x^{\prime}$, and subsequent choice of quantities satisfying (10), we will define the loans allocated to each market as,

$$
\begin{aligned}
& M_{e}^{d}\left(x^{\prime}\right) \equiv \delta\left(\frac{q_{d} w}{x}+C_{d}\right) \\
& M_{e}^{e}\left(x^{\prime}\right) \equiv \delta\left(\frac{q_{e} w}{x}+C_{e}\right) .
\end{aligned}
$$

We can readily solve for this allocation of loans by subtracting fixed costs from both sides of (11) and taking the ratio. Then using demand in (2) and (9), combined with the requirement from (10) that the expected prices $s_{d} p_{d}$ and $s_{e} p_{e}$ are equalized, it follows that the loans to the two markets are related by:

$$
\frac{M_{e}^{e}(x) / \delta-C_{e}}{M_{e}^{d}(x) / \delta-C_{d}}=\frac{\eta_{e}}{\eta_{d}}
$$


where we define the shares of demand coming from the domestic and foreign markets as:

$$
\eta_{d}=\frac{s_{d}^{\sigma} Y P^{\sigma-1}}{s_{d}^{\sigma} Y P^{\sigma-1}+s_{e}^{\sigma} Y^{*} P^{* \sigma-1}} \text { and } \eta_{e}=\frac{s_{e}^{\sigma} Y^{*} P^{* \sigma-1}}{s_{d}^{\sigma} Y P^{\sigma-1}+s_{e}^{\sigma} Y^{*} P^{* \sigma-1}} .
$$

We see from (12) that there is a simple, linear relationship between the loans allocated to the two markets. We can now proceed analogously to the domestic firms' problem. We use (11) to determine the quantity sold in each market analogous to (4), depending on the loans $M_{e}^{d}\left(x^{\prime}\right)$ and $M_{e}^{e}\left(x^{\prime}\right)$, and substitute into demand (2) and (9) for each market to determine prices. With these we obtain the firms' profits $E\left(\pi_{e}\left(x, x^{\prime}\right)\right)$. Taking the derivative of expected profits with respect to $x^{\prime}$, and setting that equal to zero, we obtain the condition for incentive compatibility:

$$
\left[\Phi_{e}^{d}\left(x, M_{e}^{d}(x)\right)+\delta\left(1-\rho_{e}\right)-1\right] \frac{M_{e}^{d \prime}(x)}{\delta}+\left[\Phi_{e}^{e}\left(x, M_{e}^{e}(x)\right)+\delta\left(1-\rho_{e}\right)-1\right] \frac{M_{e}^{e \prime}(x)}{\delta}=\rho_{e} I_{e}^{\prime}(x),
$$

where,

$$
\begin{aligned}
\Phi_{e}^{d}\left(x, M_{e}^{d}(x)\right) & \equiv\left[s_{d} p_{d}\left(\frac{\sigma-1}{\sigma}\right)\right] / \frac{w}{x} \\
& =s_{d}\left(\frac{\sigma-1}{\sigma}\right)\left(\frac{M_{e}^{d}(x)}{\delta}-C_{d}\right)^{-\frac{1}{\sigma}}\left(\frac{x P}{w}\right)^{\frac{\sigma-1}{\sigma}} Y^{\frac{1}{\sigma}}, \\
\Phi_{e}^{e}\left(x, M_{e}^{e}(x)\right) & \equiv\left[s_{e} p_{e}\left(\frac{\sigma-1}{\sigma}\right)\right] / \frac{w}{x} \\
& =s_{e}\left(\frac{\sigma-1}{\sigma}\right)\left(\frac{M_{e}^{e}(x)}{\delta}-C_{e}\right)^{-\frac{1}{\sigma}}\left(\frac{x P^{*}}{w}\right)^{\frac{\sigma-1}{\sigma}} Y^{* \frac{1}{\sigma}},
\end{aligned}
$$

and from the equality of expected marginal revenues in (10) we have that,

$$
\Phi_{e}^{d}\left(x, M_{e}^{d}(x)\right)=\Phi_{e}^{e}\left(x, M_{e}^{e}(x)\right)
$$

The interpretation of these conditions is analogous to what we obtained for domestic firms. The

values $\Phi_{e}^{d}$ and $\Phi_{e}^{e}$ are the ratio of expected marginal revenue to marginal costs in the two markets served by the exporter. Credit constraints would mean that $\Phi_{e}^{e}>1$ and $\Phi_{e}^{d}>1$, so the firm would be selling less in both markets than would be optimal in the absence of any risk or constraints. We now determine the magnitude of credit constraints that are optimal for the bank.

\subsection{Bank's Decision}

We do not assume that the bank can identify domestic firms and exporters, but only observes the announced productivities of firms. As in the Melitz (2003) model, firms will enter into domestic production and export based on the profitability of these activities. This means that the cutoff 
domestic firm with productivity $\underline{x}_{d}$ is defined by the zero-cutoff-profit condition $E\left(\pi_{d}\left(\underline{\mathrm{x}}_{d}, \underline{\mathrm{x}}_{d}\right)\right)=0$, and the cutoff exporter with productivity $\underline{\mathrm{x}}_{e}$ by the condition $E\left(\pi_{d}\left(\underline{\mathrm{x}}_{e}, \underline{\mathrm{x}}_{e}\right)\right)=E\left(\pi_{e}\left(\underline{\mathrm{x}}_{e}, \underline{\mathrm{x}}_{e}\right)\right)$. These cutoff productivities can differ from in the Melitz (2003) model, of course, because here they are influenced by the credit conditions offered by banks. A standard property of firm profits under any incentive-compatible policy is that they must be non-deceasing in the true productivity, i.e. $E\left(\pi_{d}(x, x)\right)$ and $E\left(\pi_{e}(x, x)\right)$ are non-decreasing in $x .{ }^{7}$ We will identify additional conditions below needed to ensure that the cutoff exporter, in particular, is well defined. ${ }^{8}$

The monopolistic bank chooses the loans given to domestic firms subject to the incentivecompatibility condition (6), and chooses the loans given to exporters for the domestic market $\left(M_{e}^{d}(x)\right)$ and for export market $\left(M_{e}^{e}(x)\right)$, subject to the incentive-compatibility conditions (14) and the equality of marginal revenue (16). The bank's problem is then to choose $M_{d}(x), M_{e}^{d}(x), M_{e}^{e}(x), I_{d}(x)$ and $I_{e}(x)$ to maximize its profits:

$$
\begin{aligned}
& \max _{M, I} \int_{\underline{\underline{x}}_{d}}^{\underline{\mathrm{x}}_{e}}\left(\rho_{d} I_{d}(x)-\left(1-\rho_{d}\right)\left(M_{d}(x)-K_{d}\right)-i \tau_{d} M_{d}(x)\right) f(x) d x \\
& \quad+\int_{\underline{\mathrm{x}}_{e}}^{\infty}\left(\rho_{e} I_{e}(x)-\left(1-\rho_{e}\right)\left(M_{e}(x)-K_{e}\right)-i \tau_{d} M_{e}^{d}(x)-i \tau_{e} M_{e}^{e}(x)\right) f(x) d x \\
& \text { s.t. (6) if } x \in\left[\underline{\mathrm{x}}_{d}, \underline{\mathrm{x}}_{e}\right) \text {, and (14) and (16) if } x \in\left[\underline{\mathrm{x}}_{e}, \infty\right),
\end{aligned}
$$

where $i$ is the opportunity cost of lending the loan for one unit of period and $\tau_{d}$ and $\tau_{e}$ are the length of the periods that the firm has to hold the loans in the domestic and export market respectively, as defined earlier. The probability density function of firms' productivity distribution is $f(x)$.

The maximization problem (17) is solved in two steps. First, we determine the loan schedule that maximizes bank's profit, which is an optimal control problem analyzed in Appendix A. The derivative of the optimal loan schedules will be related to the derivative of the interest payments through the incentive-compatibility conditions (6) and (14). But that still leaves open the initial level of interest payments for the cutoff domestic and exporting firms: these initial interest payments will in fact determine the productivity levels $\underline{x}_{d}$ and $\underline{x}_{e}$ for these firms. So the second step in the optimization problem for the bank is to determine the optimal initial interest payments for these cutoff firms, or equivalently, solving for the optimal cutoff productivities and consequently obtaining the implied initial interest payments.

\footnotetext{
${ }^{7}$ This is established in Baron and Myerson (1982), and subsequent literature.

${ }^{8}$ See note 9 and Appendix A.3.
} 


\subsubsection{The Loan Schedules}

The solution for the optimal loan schedules for the bank is simplified using the fact that the credit constraints in the domestic and export market must satisfy (16). In addition the loans to domestic and export production of the exporter are linearly related by (12), so we only need to analyze one of these, say $M_{e}^{d}$, in addition to the loans $M_{d}$ provided to domestic firms. It is shown in Appendix A that the optimal loan schedules for the bank satisfies the following conditions:

$$
\begin{aligned}
\Phi_{d}\left(x, M_{d}(x)\right) & =\left(1+i \delta \tau_{d}\right)\left[1-\left(\frac{\sigma-1}{\sigma}\right) \frac{1-F(x)}{x f(x)}\right]^{-1}, \\
\Phi_{e}^{d}\left(x, M_{e}^{d}(x)\right) & =\Phi_{e}^{e}\left(x, M_{e}^{e}(x)\right)=\left[1+i \delta\left(\tau_{d} \eta_{d}+\tau_{e} \eta_{e}\right)\right]\left[1-\left(\frac{\sigma-1}{\sigma}\right) \frac{1-F(x)}{x f(x)}\right]^{-1},
\end{aligned}
$$

where $\eta_{d}$ and $\eta_{e}$ denotes the relative size of the domestic market and the export market respectively, as in (13), and $F(x)$ is the cumulative density function of $x$. Substituting the full expressions for $\Phi_{d}\left(x, M_{d}(x)\right)$ from $(7)$ or $\Phi_{e}^{d}\left(x, M_{e}^{d}(x)\right)$ and $\Phi_{e}^{e}\left(x, M_{e}^{e}(x)\right)$ from (15) into the above conditions, we obtain nonlinear equations defining the loan schedules for domestic firms and exporters.

To simplify this solution, we consider a Pareto distribution for firms productivity, $F(x)=$ $1-(1 / x)^{\theta}, x \geq 1$, where $\theta$ is the shape parameter. Then the credit constraints above become constant values:

$$
\begin{aligned}
\Phi_{d}\left(x, M_{d}(x)\right) & =\bar{\Phi}_{d} \equiv\left(1+i \delta \tau_{d}\right)\left(1-\frac{\sigma-1}{\sigma \theta}\right)^{-1} \\
\Phi_{e}^{d}\left(x, M_{e}^{d}(x)\right) & =\Phi_{e}^{e}\left(x, M_{e}^{e}(x)\right)=\bar{\Phi}_{e} \equiv\left[1+i \delta\left(\tau_{d} \eta_{d}+\tau_{e} \eta_{e}\right)\right]\left(1-\frac{\sigma-1}{\sigma \theta}\right)^{-1}
\end{aligned}
$$

The weak condition $\theta>(\sigma-1) / \sigma$, as we assume holds, is sufficient for $\bar{\Phi}_{d}$ and $\bar{\Phi}_{e}$ to be greater than unity. The loan schedules are solved from (7) and (15) as:

$$
\begin{aligned}
\frac{M_{d}(x)}{\delta} & =\left(\frac{\sigma-1}{\sigma}\left(\frac{x}{w} P\right)^{\frac{\sigma-1}{\sigma}} Y^{\frac{1}{\sigma}}\right)^{\sigma}\left(\frac{\bar{\Phi}_{d}}{s_{d}}\right)^{-\sigma}+C_{d} \\
\frac{M_{e}^{d}(x)}{\delta} & =\left(\frac{\sigma-1}{\sigma}\left(\frac{x}{w} P\right)^{\frac{\sigma-1}{\sigma}} Y^{\frac{1}{\sigma}}\right)^{\sigma}\left(\frac{\bar{\Phi}_{e}}{s_{d}}\right)^{-\sigma}+C_{d} \\
\frac{M_{e}^{e}(x)}{\delta} & =\left(\frac{\sigma-1}{\sigma}\left(\frac{x}{w} P^{*}\right)^{\frac{\sigma-1}{\sigma}} Y^{* \frac{1}{\sigma}}\right)^{\sigma}\left(\frac{\bar{\Phi}_{e}}{s_{e}}\right)^{-\sigma}+C_{e} .
\end{aligned}
$$

With these loan schedules, firms will produce a constant fraction of their credit-free quantity in 
each market,

$$
\begin{aligned}
& q_{d}(x)=q_{d}^{o}(x)\left(\Phi_{d}\right)^{-\sigma} \\
& q_{d}^{e}(x)=q_{d}^{o}(x)\left(\bar{\Phi}_{e}\right)^{-\sigma} \\
& q_{e}^{e}(x)=q_{e}^{o}(x)\left(\bar{\Phi}_{e}\right)^{-\sigma}
\end{aligned}
$$

where $q_{d}^{o}(x)=\left(\frac{1}{s_{d}} \frac{\sigma}{\sigma-1} \frac{w}{x}\right)^{-\sigma} \frac{Y}{P^{1-\sigma}}$ and $q_{e}^{o}(x)=\left(\frac{1}{s_{e}} \frac{\sigma}{\sigma-1} \frac{w}{x}\right)^{-\sigma} \frac{Y^{*}}{P^{* 1-\sigma}}$ are the chosen level of production in the domestic market and export market, respectively, in the presence of project risk but without any need for credit.

Examining the features of these solutions (19), we see that credit constraints for domestic firms and exporters apply, meaning that $\bar{\Phi}_{d}>1$ and $\bar{\Phi}_{e}>1$, even if $i=0$ in (19). Thus, even when the banks has no opportunity cost of making loans, a credit constraint is still needed to ensure incentive compatibility. When $i>0$ then the credit constraint is further increased and we see from (20) that loans are reduced. It is intuitive that the bank will restrict loans as its opportunity cost rises. Furthermore the opportunity cost is measured relative to the time required for the domestic and foreign loans, or $\tau_{d}$ and $\tau_{e}$, respectively. We have assumed that $\tau_{e}>\tau_{d}$, from which it follows that the credit constraint $\bar{\Phi}_{e}$ for exporters in either their domestic or export markets exceeds $\bar{\Phi}_{d}$ for domestic firms in (19), when $i>0$. This result will be the key testable implication in our empirical application.

\subsubsection{The Cutoff Productivity Levels}

The solutions for the loan schedules and credit constraints, combined with the incentive-compatibility constraints, immediately imply the slope for the interest payment schedules. But the entire schedules are not pinned down until we also determine their initial values. As discussed above, the initial interest payment for a domestic firm will determine $\underline{x}_{d}$ via the zero-cutoff-profit condition $E\left(\pi_{d}\left(\underline{\mathrm{x}}_{d}, \underline{\mathrm{x}}_{d}\right)\right)=0$, and likewise the initial interest payment for the marginal exporter will determine $\underline{\mathrm{x}}_{e}$ via the condition $E\left(\pi_{d}\left(\underline{\mathrm{x}}_{e}, \underline{\mathrm{x}}_{e}\right)\right)=E\left(\pi_{e}\left(\underline{\mathrm{x}}_{e}, \underline{\mathrm{x}}_{e}\right)\right)$. So we can solve for the initial interest payments by differentiating (17) with respect to $\underline{x}_{d}$ and $\underline{x}_{e}$, and using these first-order conditions to determine the initial interest payments, as discussed in Appendix A.

By taking the first derivative of (17) with respect to $\underline{x}_{d}$, we can get the loan and the interest 
payment for the cutoff domestic firm,

$$
\begin{aligned}
& \frac{M_{d}\left(\underline{\mathrm{x}}_{d}\right)}{\delta}=\sigma C_{d} \\
& \rho_{d} I_{d}\left(\underline{\mathrm{x}}_{d}\right)=\left[\Phi_{d}+\delta\left(1-\rho_{d}\right)-1\right] \frac{M_{d}\left(\underline{\mathrm{x}}_{d}\right)}{\delta}-\left(1-\rho_{d}\right) K_{d} .
\end{aligned}
$$

Consequently, the interest payment for the domestic firms is:

$$
\rho_{d} I_{d}(x)=\left[\bar{\Phi}_{d}+\delta\left(1-\rho_{d}\right)-1\right] \frac{M_{d}(x)}{\delta}-\left(1-\rho_{d}\right) K_{d}
$$

The amount $\sigma C_{d}$ appearing in (22) is identical to the total costs of the first-best production for the cutoff producer in Melitz (2003). Despite this, the cutoff productivity $\underline{x}_{d}$ differs from that in Melitz (2003), because the domestic firm faces a credit constraint and therefore produces less than the first-best. It follows that $\sigma C_{d}$ finances the costs of a firm with productivity above the first-best cutoff productivity in Melitz (2003). That productivity is obtained by combining (22) with the loan schedules in (20), to solve for the cutoff productivity as,

$$
\underline{\mathrm{x}}_{d}=w\left(\left(\frac{\sigma}{\sigma-1}\right)\left(\frac{(\sigma-1) C_{d}}{s_{d}^{\sigma} Y P^{\sigma-1}}\right)^{\frac{1}{\sigma}} \bar{\Phi}_{d}\right)^{\frac{\sigma}{\sigma-1}} .
$$

Our finding that $\bar{\Phi}_{d}>1$ means that this cutoff productivity exceeds that in Melitz (2003), which is obtained when $\bar{\Phi}_{d}=1$. Therefore, the credit constaint $\bar{\Phi}_{d}>1$ not only reduces the intensive margin of production for domestic firms, it also reduces their extensive margin. This cutoff productivity is implemented by the bank charging the interest shown in (23). Notice that the bank only cares about the total expected payments $\rho_{d} I_{d}\left(\underline{\mathrm{x}}_{d}\right)+\left(1-\rho_{d}\right) K_{d}$, including collateral.

Taking the first derivative of (17) with respect to $\underline{x}_{e}$, we obtain the solution for the initial loan and interest payment for the cutoff exporter, which are slightly more complicated:

$$
\begin{aligned}
& \frac{M_{e}\left(\underline{\mathrm{x}}_{e}\right)}{\delta}=(\Delta(\sigma-1)+1) C_{e}+C_{d}, \\
& \rho_{e} I_{e}\left(\underline{\mathrm{x}}_{e}\right)=\left(\bar{\Phi}_{e}+\delta\left(1-\rho_{e}\right)-1\right) \frac{M_{e}\left(\underline{\mathrm{x}}_{e}\right)}{\delta}+\Theta,
\end{aligned}
$$

where the parameters in the above equations are:

$$
\begin{aligned}
\Delta & \equiv\left(\frac{1+i \delta \tau_{e}}{1+i \delta\left(\tau_{d} \eta_{d}+\tau_{e} \eta\right)}\right)\left(1-\left(\frac{1+i \delta\left(\tau_{d} \eta_{d}+\tau_{e} \eta_{e}\right)}{1+i \delta \tau_{d}}\right)^{\sigma-1} \eta_{d}\right)^{-1} \\
\Theta & \equiv \frac{i \delta\left(\tau_{e}-\tau_{d}\right)}{\left(1-\frac{\sigma-1}{\sigma \theta}\right)}\left(\eta_{d} C_{e}-\eta_{e} C_{d}\right)-\left(1-\rho_{e}\right) K_{e}
\end{aligned}
$$


Consequently, the interest payment schedule for exporters is then:

$$
\rho_{e} I_{e}(x)=\left(\bar{\Phi}_{e}+\delta\left(1-\rho_{e}\right)-1\right) \frac{M_{e}(x)}{\delta}+\Theta .
$$

To interpret these parameters, consider first the case where $i=0$. Then we see that $\Delta=$ $1 /\left(1-\eta_{d}\right)=1 / \eta_{e}$, or the inverse of the relative size of the export market. It can be confirmed that the amount $M_{e}^{e}\left(\underline{\mathrm{x}}_{e}\right) / \delta$ given by (26) is then precisely equal to the export costs of first-best production for the cutoff exporter in the Melitz (2003) model. But for the same reason as above, the cutoff productivity is higher in our setting where firms are credit constrained. Specifically, combining (26) with the loan schedules in (20) we can explicitly solve for the cutoff exporter productivity as,

$$
\underline{\mathrm{x}}_{e}=w\left(\left(\frac{\sigma}{\sigma-1}\right)\left(\frac{\Delta(\sigma-1) C_{e}}{s_{d}^{\sigma} Y P^{\sigma-1}+s_{e}^{\sigma} Y^{*} P^{* \sigma-1}}\right)^{\frac{1}{\sigma}} \bar{\Phi}_{e}\right)^{\frac{\sigma}{\sigma-1}} .
$$

It is readily confirmed that $\Delta$ is increasing in $i$ under our maintained assumption that $\tau_{e}>\tau_{d} \cdot{ }^{9}$ Combined with the fact that $\bar{\Phi}_{e}>1$, this means that the cutoff productivity obtained from (29) exceeds that in Melitz (2003), which is obtained when $\Delta=1 / \eta_{e}$ and $\bar{\Phi}_{e}=1$. Thus, the credit constraint implies a reduction in exports on both the intensive and extensive margins, and this reduction exceeds what we found for the domestic market, since $\bar{\Phi}_{e}>\bar{\Phi}_{d}$ when $i>0$. This cutoff productivity for the exporter is implemented by the bank charging the interest shown in (27), which depends on the term $\Theta$. Under our assumption that $\tau_{e}>\tau_{d}$, the first term in $\Theta$ is greater than zero if and only if $\eta_{d} / C_{d}>\eta_{e} / C_{e}$, i.e. the domestic market size relative to fixed costs exceeds that for the export market. This assumption is commonly made in the Melitz (2003) model and we also use it here.

In our solutions so far, neither the default risk nor the level of collateral enter the credit constraints nor affect the extensive margin of producing firms. The reason for this result is that the bank only cares about the total expected payments it receives, which includes interest and collateral, as seen by moving the collateral term to the left in (23) and (27). As collateral rises, interest payments correspondingly fall, but no other variables or margins in the model are affected. This special feature of the solution will not occur, however, when we introduce the "cash flow

\footnotetext{
${ }^{9}$ There is an upper bound on $i$, since $\left(\frac{1+i \delta\left(\tau_{d} \eta_{d}+\tau_{e} \eta_{e}\right)}{1+i \delta \tau_{d}}\right)^{\sigma-1} \eta_{d}<1$ is needed to ensure that $E\left(\pi_{e}(x, x)\right)$ has a larger slope than $E\left(\pi_{d}(x, x)\right)$. This slope condition holds automatically in the Melitz model, but here we need to add it an extra assumption in order to get a well-defined solution for the marginal exporter.
} 
constraint" next, which states that a firm needs enough revenue on hand to pay back the loan and interest to the bank.

\subsection{Cash Flow Constraint}

Manova (2008) uses a cash flow constraint (but referring to it as a credit constraint) to explain why exporters might be limited in their loans: they need enough cash from sales revenue to repay the loan plus interest. We now explore whether such constraints will operate differently for domestic and exporting firms. Specifically, provided that the incentive compatibility condition ensures that firms claim their true productivities, the cash flow constraints for domestic firms and exporters are,

$$
\begin{aligned}
& C F_{d}(x)=p_{d} q_{d}-M_{d}(x) / \delta-I_{d}(x) \geq 0 \\
& C F_{e}(x)=p_{d} q_{d}+p_{e} q_{e}-M_{e}(x) / \delta-I_{e}(x) \geq 0 .
\end{aligned}
$$

Notice that these constraints ignore the probabilities $s_{d}$ and $s_{e}$ that domestic and export revenue are received, and also the probabilities $\rho_{d}$ and $\rho_{e}$ that domestic firms and exporters repay the bank. Rather, these are ex post constraints that apply when projects are successful and there is no default by the firm. Generally, we view the default probabilities of the firms as bounded above by the project-success probabilities, i.e. $\rho_{d} \leq s_{d}$, and $\rho_{e} \leq s_{e}$. When these inequalities are strict then we will find that the cash flow constraints are tighter than the zero-cutoff-profit constraints, which are stated in terms of expected profits, and therefore might be violated in the equilibrium we have already derived. We do not want to consider values of the default probabilities that are too low, however, since in that case the cash flow constraints in (30) and (31) might not be monotonically increasing in $x$. That monotonicity condition is assumed by Manova (2008), who argues that small firms are more likely to face a cash flow constraint than large firms. We can ensure that $C F_{d}^{\prime}(x)>0$ and $C F_{e}^{\prime}(x)>0$ in our model by the sufficient conditions: $\rho_{d}>\frac{\bar{\Phi}_{d}-(1-\delta)}{\frac{\sigma}{(\sigma-1) s_{d}} \bar{\Phi}_{d}-(1-\delta)}$ and $\rho_{e}>\frac{\bar{\Phi}_{e}-(1-\delta)}{\frac{\sigma}{(\sigma-1)}\left(\frac{\eta_{d}}{s_{d}}+\frac{\eta_{e}}{s_{e}}\right) \bar{\Phi}_{e}-(1-\delta)}$, which we assume are satisfied.

When the cash flow constraints are violated in the equilibrium we have already described, then the marginal firm cannot afford to repay the bank. We suppose that the bank anticipates this and raises the cutoff productivity at which it lends to domestic or export firms. Specifically, we solve for these cutoff productivities by the condition that the cash flow equals zero. But first, we need to check whether the cash flow constraint is binding or not in our previous solution.

We substitute the cutoff productivities, (25) and (29), into the two cash flow constraints, (30) 
and (31), and follow Manova (2008) in assuming that the collateral is a fraction, $k$, of the fixed costs, i.e. $K_{d}=k C_{d}$ and $K_{e}=k\left(C_{d}+C_{e}\right)$. Then we find that the cash flow constraint for the cutoff domestic firm is satisfied if and only if:

$$
k \geq \sigma\left(\left(1-\frac{\rho_{d}}{s_{d}}\right) \frac{\bar{\Phi}_{d}}{1-\rho_{d}}-(1-\delta)\right)
$$

In addition, the cash flow constraint for the exporter is satisfied if and only if:

$$
\begin{aligned}
k & \geq\left(\left(\left(1-\frac{\rho_{e}}{s_{d}} \eta_{d}-\frac{\rho_{e}}{s_{e}} \eta_{e}\right) \Delta \sigma-(\Delta-1)\right) C_{e}+C_{d}\right) \frac{\bar{\Phi}_{e}}{\left(1-\rho_{e}\right)\left(C_{d}+C_{e}\right)} \\
& -(1-\delta)\left(\frac{\Delta(\sigma-1) C_{e}}{C_{d}+C_{e}}+1\right)+\frac{i \delta\left(\tau_{e}-\tau_{d}\right)}{\left(1-\frac{\sigma-1}{\sigma \theta}\right)} \frac{\left(\eta_{d} C_{e}-\eta_{e} C_{d}\right)}{\left(1-\rho_{e}\right)\left(C_{d}+C_{e}\right)}
\end{aligned}
$$

To interpret (32), suppose that the probability of a successful project for a domestic firm, $s_{d}$, equals the probability of repaying its loan, $\rho_{d}$. Then it is immediate that $(32)$ is satisfied even if $k=0$, that is, even if the domestic firm has no collateral at all. If it is more likely that the firm defaults on its bank loan, so that $\rho_{d}<s_{d}$, and by enough so that the right (32) is strictly positive, then the firm will need some positive level of collateral to satisfy the cash flow constraint. The benefit of collateral is that it directly reduces the interest payment to the bank, from (23), and therefore makes the cash flow constraint (30) easier to satisfy.

The condition for the cash flow constraint for the exporter to be satisfied is more complex. Continuing with the assumption $\rho_{d}=s_{d}$, let us also assume $i=0$ and $\rho_{e}=s_{e}$ but that the exporter faces greater project risk in its export market and specify $s_{e} / s_{d}=(\sigma-1) / \sigma<1$. In this case, (33) becomes:

$$
k \geq \frac{\bar{\Phi}_{e}}{1-\rho_{e}}\left(\frac{C_{d}}{C_{d}+C_{e}}\right)-(1-\delta)\left(\frac{(\sigma-1) C_{e}}{\eta_{e}\left(C_{d}+C_{e}\right)}+1\right)
$$

The first term on the right is positive, so depending on the magnitude of the second term, the exporter might need positive collateral to satisfy its cash flow constraint. This finding arises from the greater risk faced by the exporter in its foreign market, and shows that it is quite possible for the cash flow constraint to be binding for the exporters but not for the domestic firm, which is the case we shall focus on.

When the cash flow constraint is not binding for the domestic firm, that cutoff producer is again determined by the zero-cutoff-profit condition $E\left(\pi_{d}\left(\underline{\mathrm{x}}_{d}, \underline{\mathrm{x}}_{d}\right)\right)=0$, leading to the solution (25) as before. But the cutoff productivity for the exporter is now determined by the binding cash flow 
constraint, $C F_{e}\left(\underline{\mathrm{x}}_{e}\right)=0$, while the interest payments for the cutoff exporter are set to ensure that $E\left(\pi_{e}\left(\underline{\mathrm{x}}_{e}, \underline{\mathrm{x}}_{e}\right)\right)=E\left(\pi_{d}\left(\underline{\mathrm{x}}_{e}, \underline{\mathrm{x}}_{e}\right)\right) \cdot{ }^{10}$ It follows that when $\delta=1$ and $i=0$ the new cutoff exporter is:

$$
\underline{\mathrm{x}}_{e}=w\left(\left(\frac{\sigma}{\sigma-1}\right)\left(\frac{A_{1} C_{d}-A_{2} k\left(1-\rho_{e}\right)\left(C_{d}+C_{e}\right)}{s_{d}^{\sigma} Y P^{\sigma-1}+s_{e}^{\sigma} Y^{*} P^{* \sigma-1}}\right)^{\frac{1}{\sigma}} \bar{\Phi}_{e}\right)^{\frac{\sigma}{\sigma-1}}
$$

where $A_{1}=\bar{\Phi}_{d} A_{2}$ and $A_{2}=\left(\left(\eta_{d}-\left(1-\frac{\rho_{e}}{s_{d}} \eta_{d}-\frac{\rho_{e}}{s_{e}} \eta_{e}\right) \sigma\right) \frac{\bar{\Phi}_{e}}{\sigma-1}\right)^{-1}$. The credit constraint for exporters $\bar{\Phi}_{e}$ still enters (34), and a tightening of this constraint raises $\underline{x}_{e}$ and reduces the extensive margin of exports, as we found previously. But this negative effect on the extensive margin is now offset by the exporter having higher collateral $k$ in (34), as we shall test empirically.

\section{$3 \quad$ Estimating Equation and Data}

\subsection{Empirical Specification}

We can use our results above to derive a linear relationship between expected interest payments and expected revenue of the firm, where the coefficients of this linear relationship depend on the credit constraints faced by domestic firms and exporters. This equation will be tested using data on Chinese firms.

To derive this relationship, start with domestic firms. The loans $M_{d}(x) / \delta$ are needed to finance total costs, so $M_{d}(x) / \delta-C_{d}$ are needed for variable costs. The ratio of expected marginal revenue to marginal costs is $\bar{\Phi}_{d}$, and the ratio of price to marginal revenue for CES demand is $\sigma /(\sigma-1)$. Therefore, the total expected sales revenue $s_{d} p_{d} q_{d}$ obtained from the working-capital loans of $M_{d}(x)$ are $s_{d} p_{d} q_{d}=\left[M_{d}(x) / \delta-C_{d}\right] \bar{\Phi}_{d} \sigma /(\sigma-1)$.

In our data we will not observe total loans to firms, but rather, total interest payments. From the incentive-compatibility condition (6) combined with the initial interest payments (23), it is immediate that,

$$
\rho_{d} I_{d}(x)=\left[\bar{\Phi}_{d}+\delta\left(1-\rho_{d}\right)-1\right] \frac{M_{d}(x)}{\delta}-\left(1-\rho_{d}\right) K_{d}, \text { for } x \in\left[\underline{\mathrm{x}}_{d}, \underline{\mathrm{x}}_{e}\right) .
$$

Substituting for the expression for expected revenue, we obtain:

$$
s_{d} p_{d} q_{d}=\frac{\sigma}{\sigma-1} \bar{\Phi}_{d}\left(\frac{\rho_{d} I_{d}(x)+\left(1-\rho_{d}\right) K_{d}}{\bar{\Phi}_{d}+\delta\left(1-\rho_{d}\right)-1}-C_{d}\right) .
$$

\footnotetext{
${ }^{10}$ See Appendix A.2.
} 
A similar line of argument will show that the relationship between expected revenue and loans for an exporting firm is,

$$
\begin{aligned}
& s_{d} p_{d} q_{d}+s_{e} p_{e} q_{e} \\
& =\frac{\sigma}{\sigma-1} \bar{\Phi}_{e}\left[M_{e}(x) / \delta-C_{d}-C_{e}\right] \\
& =\frac{\sigma}{\sigma-1} \bar{\Phi}_{e}\left(\frac{\rho_{e} I_{e}(x)-\Theta}{\bar{\Phi}_{e}+\delta\left(1-\rho_{e}\right)-1}-C_{d}-C_{e}\right)
\end{aligned}
$$

where the first line follows from the fact that the exporter faces the credit constraint of $\bar{\Phi}_{e}$ in the domestic and export markets; and the second equality from (27).

To summarize the above relations, let us denote the expected payments to the bank, the expected revenue and fixed costs as,

$$
\begin{aligned}
& E(I(x))=\left\{\begin{array}{l}
\rho_{d} I_{d}(x)+\left(1-\rho_{d}\right) K_{d}(x) \text { if } \mathrm{x} \in\left[\underline{\mathrm{x}}_{d}, \underline{\mathrm{x}}_{e}\right] \\
\rho_{e} I_{e}(x)+\left(1-\rho_{e}\right) K_{e}(x) \text { if } \mathrm{x} \in\left[\underline{\mathrm{x}}_{e}, \infty\right],
\end{array}\right. \\
& E(r(x))=\left\{\begin{array}{c}
s_{d} p_{d} q_{d} \text { if } \mathrm{x} \in\left[\underline{\mathrm{x}}_{d}, \underline{\mathrm{x}}_{e}\right] \\
s_{d} p_{d} q_{d}+s_{e} p_{e} q_{e} \text { if } \mathrm{x} \in\left[\underline{\mathrm{x}}_{e}, \infty\right],
\end{array}\right.
\end{aligned}
$$

and,

$$
C=\left\{\begin{array}{c}
C_{d} \text { if } \mathrm{x} \in\left[\underline{\mathrm{x}}_{d}, \underline{\mathrm{x}}_{e}\right] \\
C_{d}+C_{e} \text { if } \mathrm{x} \in\left[\underline{\mathrm{x}}_{e}, \infty\right] .
\end{array}\right.
$$

For convenience, we have included collateral in our definition of bank payments in (36), but in the estimation will separate these variables. In addition, define $\mathbf{1}_{\left\{x \underline{\mathbf{x}}_{e}\right\}}$ as an indicator variable which takes one for $x \geq \underline{x}_{e}$ and zero otherwise. Using these various definitions, we obtain a linear relation between expected revenue and bank payments for firm $j$ in year $t$,

$$
E_{j t}(r(x))=\beta_{0} C+\beta_{1} C \mathbf{1}_{\left\{x_{j t} \underline{x}_{e}\right\}}+\beta_{2} E_{j t}(I(x))+\beta_{3} E_{j t}(I(x)) \mathbf{1}_{\left\{x_{j t} \underline{x}_{e}\right\}}+\beta_{4} i \mathbf{1}_{\left\{x_{j t} \geq \underline{x}_{e}\right\}},
$$

where the coefficients are obtained from above as:

$$
\begin{aligned}
& \beta_{0}=-\frac{\sigma}{\sigma-1} \bar{\Phi}_{d}<0, \\
& \beta_{1}=-\frac{\sigma}{\sigma-1}\left(\bar{\Phi}_{e}-\bar{\Phi}_{d}\right)<0, \\
& \beta_{2}=\frac{\sigma}{\sigma-1}\left(\frac{\bar{\Phi}_{d}}{\bar{\Phi}_{d}+\delta\left(1-\rho_{d}\right)-1}\right)>0, \\
& \beta_{3}=\frac{\sigma}{\sigma-1}\left(\frac{\bar{\Phi}_{e}}{\bar{\Phi}_{e}+\delta\left(1-\rho_{e}\right)-1}-\frac{\bar{\Phi}_{d}}{\bar{\Phi}_{d}+\delta\left(1-\rho_{d}\right)-1}\right)<0, \\
& \beta_{4}=-\frac{\sigma}{\sigma-1}\left(\frac{\bar{\Phi}_{e}\left(\eta_{d} C_{e}-\eta_{e} C_{d}\right)}{\bar{\Phi}_{e}+\delta\left(1-\rho_{e}\right)-1}\right) \frac{\delta\left(\tau_{e}-\tau_{d}\right)}{\left(1-\frac{\sigma-1}{\sigma \theta}\right)}<0 .
\end{aligned}
$$


The coefficients $\beta_{0}$ and $\beta_{1}$ are negative because higher fixed costs reduce the amount of the loan available to cover variable costs, and therefore reduce expected revenue. The coefficient $\beta_{2}$, which multiplies the bank payments, is positive, indicating that a larger payments are associated with larger revenue. On the other hand, the coefficient $\beta_{3}$, which multiplies the interaction between bank payments and the export indicator, is negative provided that $\delta\left(1-\rho_{e}\right)<1, \rho_{e} \leq \rho_{d}, \tau_{e}>\tau_{d}$ and $i>0$, so that $\bar{\Phi}_{e}>\bar{\Phi}_{d}$. This negative coefficient reduces the sales revenue for exporters given any bank payments, reflecting the extra credit constraint imposed on them. But notice that exporters having higher default risk than domestic firms, $\left(1-\rho_{e}\right)>\left(1-\rho_{d}\right)$, will also contribute to reducing $\beta_{3}$ (making it more negative), similar to the impact of the credit constraints $\bar{\Phi}_{e}>\bar{\Phi}_{d}$.

Finally, the coefficient $\beta_{4}$ is negative provided that $\tau_{e}>\tau_{d}$ and $\eta_{d} / C_{d}>\eta_{e} / C_{e}$. Notice that in the estimating equation (37), $\beta_{4}<0$ multiplies the interest rate time the export indicator, so higher interest rates - reflecting greater opportunity cost for bank loans - are associated with lower revenue for exporters. The presence of this term can be traced back to $\Theta$ in (27), which determined the interest payments for the cutoff exporter. As interest rates rise, or the time-lag for exports increases, the bank faces higher opportunity costs in making export loans and passes these on as higher interest payments, thereby reducing the extensive margin of exports. It follows that revenue relative to interest payments falls for exporters.

The structural equation (37) is derived from our model and does not have any error term: it is an exact linear relation between the variables. But an error term will be implied by the fact that the coefficients $\beta=\left(\beta_{0}, \ldots, \beta_{4}\right)$ depend on other structural parameters, and so do the variables themselves. For example, an increase in domestic firms' default probability $\left(1-\rho_{d}\right)$ reduces the coefficient $\beta_{2}$, while an increase in exporters' default probability $\left(1-\rho_{e}\right)$ reduces $\beta_{3}$, so that revenue falls for any payments to the bank. These results are due to the interest payments in (23) and (27). We see from those conditions that a fall in $\rho_{d}$ or $\rho_{e}$ leads to higher payments $E(I(x))$ to the bank: i.e. if firms are less likely to repay the loan then the bank charges more to the cutoff domestic firm and exporter, so an increase in the default rate is similar to a tightening of the credit constraints in this respect. ${ }^{11}$

Besides the default rate, another parameter that surely varies a great deal across firms is $\delta$, which is the fraction of total costs that must be covered by loans. At the outset we suggested that

\footnotetext{
${ }^{11}$ But in contrast to the credit constraints, the default rate does not affect loans to firms in (20). It follows that while expected payments to the bank goes up as default rises, the firm's sales revenue is not affected.
} 
$\delta$ could reflect the capital intensity of sectors and firms, and this idea will be confirmed by an initial look at the data below (Figure 1). In our model, an rise in $\delta$ increases the credit constraints in (19) when $i>0$, which lowers the amounts $M_{d}(x) / \delta$ and $M_{e}(x) / \delta$ in (20) and therefore reduces expected revenue. Interest payments are pulled in opposite directions as $\delta$ rises while $M_{d}(x) / \delta$ falls in (35), but we can verify that the structural parameters $\beta_{2}$ and $\beta_{3}$ both fall: given interest payments, firm are selling less and the extra credit constraint on exporters is tighter in sectors with the greatest need for loans.

It follows that we should write the structural parameters in (37) as depending on the identity of firms, $\beta_{j}{ }^{12}$ Summarizing all the right-hand side variables as $X_{j t}$ and expected sales as $y_{j t}$, the estimating equation is $y_{j t}=X_{j t} \beta_{j}$. In order to consistently estimate the population averages $\beta$, we re-write this equation as,

$$
y_{j t}=X_{j t} \beta+u_{j t}, \text { where } u_{j t} \equiv X_{j t}\left(\beta_{j}-\beta\right) .
$$

This is an example of a panel model with random coefficients, but we cannot assume that $X_{j t}$ are independent of $u_{j t}$ : from our discussion just above, differences in $\delta_{j}$ across firms influence both the parameters $\beta_{j}$ and $X_{j t}$. So we have a panel model with random coefficients and endogenous regressors, as analyzed by Murtazashvili and Wooldridge (2008). To obtain consistent estimates of the population averages $\beta$, they recommend a fixed effects-instrumental variable estimator, such as FE-2SLS, as we shall use. We will need an instrumental variable that is uncorrelated with variations in model parameters across firms - such as the default rates $\rho_{d}$ and $\rho_{e}$ or the need for loans $\delta$ - but correlated with the variation in interest payments that does not reflect these parameters. For this purpose we will use total factor productivity (TFP) of firms. The measurement of this variable is discussed below.

\subsection{Firm-level Data}

The sample used in this paper comes from a rich Chinese firm-level panel data set which covers more than 160,000 manufacturing firms per year for the years 2000-2008. The number of firms doubled from 162,885 in 2000 to 412,212 in $2008 .{ }^{13}$ The data are collected and maintained by

\footnotetext{
${ }^{12}$ Variation in $\beta$ over time, such as due to changes in the default rate, will be introduced explicitly into the estimation.

${ }^{13}$ Data in 2008, which is still not formally released and only available in a trial version, do not have information on firm's ID. So we use other available common variables to merge with data on 2007 and obtain 336,480 observations, which is almost identical to number of observations in 2007 (i.e., 336,768 firms).
} 
China's National Bureau of Statistics in an annual survey of manufacturing enterprises. ${ }^{14}$ It covers two types of manufacturing firms: (1) all state-owned enterprises (SOEs); (2) non-SOEs whose annual sales are more than five million Renminbi (which is equivalent to around $\$ 735,000$ under current exchange rate). The non-SOEs can be either multinationals or not. The data set includes more than 100 financial variables listed in the main accounting sheets of all these firms.

Although this data set contains rich information, a few variables in the data set are noisy and misleading due, in large part, to the mis-reporting by some firms. ${ }^{15}$ We hence clean the sample and rule out outliers by using the following criteria: first, the key financial variables (such as total assets, net value of fixed assets, sales, gross value of industrial output) cannot be missing; otherwise those observations are dropped. Secondly, the number of employees hired for a firm must not be less than 10 people. ${ }^{16}$ In addition, following Cai and Liu (2009), and guided by the General Accepted Accounting Principles, we delete observations if any of the following rules are violated: (i) the total assets must be higher than the liquid assets; (ii) the total assets must be larger than the total fixed assets; (iii) the total assets must be larger than the net value of the fixed assets; (iv) a firm's identification number cannot be missing and must be unique; and (v) the established time must be valid. In particular, observations in which the opening year is after 2008 or the opening month is later than December or earlier than January are dropped as well.

Since multinationals potentially stand out in the data, we treated them specially. We first construct a dummy for multinationals to distinguish foreign from non-foreign firms. ${ }^{17}$ In a robustness check, we consider a broader classification of multinationals by including the Hong Kong/Macao/Taiwan (H/M/T)-invested firms. ${ }^{18}$ For SOEs, the number was small enough (41,092 or $3.8 \%$ of the sample) that we decided to drop them from the estimation.

After this rigorous filter, we obtain a sample of 1,158,359 observations from the original sample

\footnotetext{
${ }^{14}$ Indeed, aggregated data on the industrial sector in the annual China's Statistical Yearbook by the Natural Bureau of Statistics (NBS) are compiled from this dataset.

${ }^{15}$ For example, information on some family-based firms, which usually did not set up formal accounting systems, is based on a unit of one Renminbi, whereas the official requirement is a unit of 1,000 Renminbi. Holz (2004) offers careful scrunity on possible measurement problems in Chinese data, especially on the aggregated level.

${ }^{16}$ Levinsohn and Petrin (2003) suggest covering all Chilean plants with at least 10 workers, and we follow their criterion.

${ }^{17}$ Specifically, multinationals include the following: foreign-invested joint-stock corporations (code: 310), foreigninvested joint venture enterprises (320), fully foreign-invested enterprise (330), and foreign-invested limited corporations (340).

${ }^{18}$ Specifically, the $\mathrm{H} / \mathrm{M} / \mathrm{T}$-owned firms includes the following firms: $\mathrm{H} / \mathrm{M} / \mathrm{T} /$ joint-stock corporations (code: 210 ), $\mathrm{H} / \mathrm{M} / \mathrm{T}$ joint venture enterprises (220), fully H/M/T-invested enterprises (230), and H/M/T-invested limited corporations (240).
} 
of 2,235,438, which accounts for around a half of the original data set during years 2000-2008. As shown in Table 1, during years 2000-2008, multinationals accounts for $10.4 \%$ of total firms but increases to $21.1 \%$ if including investment from $\mathrm{H} / \mathrm{M} / \mathrm{T}$. On average, foreign firms have higher revenue and more interest payment than domestic firms. Similarly, exporting firms, which account for $28.5 \%$ in the sample, also have higher revenue and more interest payment than firms that only sell products domestically.

In addition to the firm-level production data, we rely on another highly disaggregated productlevel trade data obtained from Chinese Customs, which records information such as types of shipments and their export values, to merge with the firm-level data set. To date, researchers have faced technical challenges to merge the two data sets. Although they both report and identification number for firms, the coding system in each data set is completely different. Hence, we rely instead on the zip code and the last seven digits of a firm's phone number to merge the data. ${ }^{19}$

\subsection{Measure of TFP}

We use the augmented Olley-Pakes (1996) approach to estimate and calculate the firms' TFP. This method is applied to our dataset of Chinese firms as follows. ${ }^{20}$ First, given that the measure of TFP requires real terms of firm's inputs (labor and capital) and output, we first adopt different price deflators for inputs and outputs. Data on input deflators and output deflators are directly from Brandt et al. (2009) in which the output deflators are constructed using "reference price" information from China's Statistical Yearbooks whereas input deflators are constructed based on output deflators and China's national input-output table (2002). ${ }^{21}$ Second, we use deflated firm's value-added to measure production since we do not include intermediate inputs (materials) as one kind of factor input. This is important because processing trade in China accounts for more than a half of its total trade since 1995. The prices of imported intermediate inputs are different from those of domestic intermediate inputs. Using China's domestic deflator to measure its imported intermediate input would raise another unnecessary estimation bias. ${ }^{22}$

Third, it is essential to construct the real investment variable when using the Olley-Pakes (1996)

\footnotetext{
${ }^{19} \mathrm{Yu}(2010)$ provides a more detailed description of the merging of the two data sets.

${ }^{20}$ Additional technical details of the Olley-Pakes (1996) approach are available on request, and also discussed in $\mathrm{Yu}(2010)$.

${ }^{21}$ Such data can be accessed via http://www.econ.kuleuven.be/public/N07057/CHINA/appendix/.

${ }^{22}$ Note that we are not able to use value-added to estimate firm's TFP in 2008 which is absent in the current trial version of the data set. We instead use industrial output to replace value-added, which raises a possible upward bias for the estimated capital coefficients and hence a possible downward bias for the TFP.
} 
approach. As usual, we adopt the perpetual inventory method to investigate the law of motion for real capital and real investment. Rather than assigning an arbitrary number for the depreciation ratio, we use the exact firm's real depreciation provided by the Chinese firm-level data set. Last but not least, given China's WTO accession in 2001, which was a positive demand shock for China's exports, we also include a WTO dummy in the Olley-Pakes estimation to capture the effect of the WTO accession.

Columns (1)-(2) of Table 2 reports the estimated elasticity coefficient of labor and capital for the thirty China's manufacturing sectors coded from 13 to 42, according to China's adjusted industrial classifications (GB/T4754), which were adopted in 2002. ${ }^{23}$ Using data from 2000-2007, on average, the estimated elasticity for labor is .399 and for capital is .278. The average (natural) logarithm of China's TFP is 4.214 over the period of $2000-2007 .{ }^{24}$ We then separate all firms in the sample to two groups: domestic firms which only sell their products at home, and exporting firms which sell their products both at home and abroad. Overall, the logarithm of TFP for domestic firms (4.258) is slightly smaller than its counterpart for exporting firms (4.196). Columns (3)-(4) of Table 2 presents the estimated TFP for domestic firms and exporting firms by manufacturing sectors.

\section{Estimation Results}

\subsection{The Credit Constraint}

In Figure 1 we show firm revenue and interest payments, taking the average over the years 2000-2008 and over 2-digit manufacturing sectors. There is a clear positive relationship between the two, as implied by our model. But we also see that some industries have higher interest payments relative to sales revenue than others. For example, some capital-intensive industries such as manufacture of chemical fibers (code in Figure 1: 28) and tobacco (code: 16) are below the diagonal, while other labor-intensive industries like computers and other electronic equipment (code: 40) are above the diagonal. These observations justify our argument that the capital-intensity of production influences $\delta$ in our model, thereby making the coefficients in (37) random across firms and the regressors endogneous. For that reason we use FE-2SLS when estimating (39), using firm TFP and its interactions with other variables as the instuments. ${ }^{25}$

\footnotetext{
${ }^{23}$ Firm data before 2002 were clustered into industrial data by adopting the old industrial classification. We concord such data so that they are consistent with data after 2002 .

${ }^{24}$ As presented in Table 1, the average log of TFP is 4.211 over the period of $2000-2008$.

${ }^{25}$ We have also adopted a one-period lag of TFP as the instrument for interest payments, and obtained very similar results to using current TFP.
} 
Table 3 first reports the OLS estimates of (39) in column (1) and then the 2SLS estimates in the remaining columns, where for simplicity, we do not include fixed costs or collateral in this initial specification. There are four endogenous variables in the estimation: (1) the firms' interest payment; (2) an interaction term between the interest payment and the export indicator; (3) an interaction term between the interest payment and the foreign firm indicator; and (4) the triple interaction between the interest payment, export indicator and foreign firm indicator. Accordingly, we adopt four instruments here: the level of firm's TFP $\left(x_{i t}\right)$; the interaction term between firm's TFP and the foreign indicator; the interaction term between firm's TFP and the export indicator; and the interaction term between firm's TFP, export indicator, and foreign firm indicator.

The OLS estimates in column (1) perform poorly, yielding coefficients that are smaller than the 2SLS estimates and sometimes of opposite sign. This is to be expected from a model with random coefficient and endogenous regressors. In contrast, the 2SLS coefficients are relatively stable in columns (2)-(5), which differ by the use of firm-specific random effects and the interaction between the export indicator and the industry-specific fixed effects. Column (5) is special because we have excluded from the sample about $10 \%$ of firms that only export, which is inconsistent with our model.

In all 2SLS estimates we find that the coefficient of interest payment, $\hat{\beta}_{2}$, is positive whereas the coefficient of the interaction between interest payment and export indicator, $\hat{\beta}_{3}$, is significantly negative but smaller in absolute value than $\hat{\beta}_{2} \cdot{ }^{26}$ Thus, after controlling for random coefficients and endogenous regressors, our estimates confirm the predictions in our theoretical model: higher interest payments lead to greater firm revenue, though interest payments have a smaller positive effect on the revenue for exporters than for non-exporters. This confirms that additional credit constraints are imposed on exporters.

The export indicator itself also has a negative coefficient in columns (2)-(5), which corresponds to a combination of $\hat{\beta}_{1}$ and $\hat{\beta}_{4}$ in (37), i.e. it combines the coefficient of the export indicator times fixed costs and the coefficient of the export indicator itself. In Table 3 we have not explicitly introduced fixed costs, so we cannot distinguish these two variables. Both coefficients are expected to be negative in the model, which is confirmed by the negative coefficient on the export indicator found in columns (2)-(5).

\footnotetext{
${ }^{26}$ The only specification where we do not find this result is when firm-specific fixed effects are used (not reported in Table 3), in which case the interaction between interest payments and the export indicator becomes insignificant.
} 
The results in Table 3 also indicate that foreign firms face a smaller credit constraint as compared to domestic firms, and that foreign exporting firms do not face any additional credit constraint as compared to foreign non-exporters. The first result is shown by the negative coefficient on the interaction between the interest payment and the foreign indicator, which is significant when firm random effects are used. The second result is shown by the positive coefficient on the triple interaction between the interest payment, export indicator and foreign indicator, which is large enough to fully offset the negative coefficient on the interest payment times the export indicator. In other words, exporting firms face an additional credit constraint, but not if they are foreign exporting firms. These results confirm the findings of Manova, Wei and Zhang (2009) that the credit constraint is weaker for multinational firms in China

Several tests are performed to verify the validity of our instruments, which are TFP and its interactions with the indicator variables. First, to check whether such instruments are "relevant", we use the Kleibergen-Paap (2006) LM $\chi^{2}$ statistic to check whether the instruments are correlated with the endogenous variables. As shown in columns (2)-(3) of Table 3, the null hypothesis that the model is under-identified is rejected at the $1 \%$ significance level. Second, the Kleibergen-Paap (2006) F statistic provides strong evidence to reject the null hypothesis that the first stage is weakly identified at a highly significance level. Finally, the first-stage estimation results shown in the lower module of Table 3 offer strong evidence to justify the validity of such instruments. In particular, in columns (2)-(5), the t-values of the four endogenous regressors are highly statistically significant. In addition, the excluded $\mathrm{F}$ statistics in the first stage are also significant. ${ }^{27}$ These tests give sufficient evidence that the instruments perform well, and therefore, the specification is well justified both theoretically and statistically.

\subsection{Impact of the Financial Crisis}

It is believed that the global financial crisis in 2008 had a significant negative impact on global trade. With the financial crisis, it is presumably more difficult for a firm to access loans from financial intermediates, which in turn shrinks their exports and total revenue. We can add year indicators to our specification to test this hypothesis for our sample of Chinese firms.

\footnotetext{
${ }^{27}$ In addition, we performed extra auxiliary regressions to check for the "exclusive restriction" of the instruments. To show that the instruments affect the regressand through and only through the endogenous variables, we follow previous work in running regressions of instruments on the residual obtained in the second-stage estimation. It turns out that the coefficients of these instruments are all highly insignificant which, to some extent, excludes other possible channels. These results are available on request.
} 
The impact of the financial crisis in our model can show up in two ways. First, the coefficient $\beta_{4}<0$ in $(37)$ is multiplied by the interest rate $i$, which reflects the added opportunity cost to banks from giving loans to exporting firms that take longer to repay. We allow for changes in the interest rate by using a year indicator interacted with the export indicator, and rising interest rates should show up as a negative interaction. The $\beta_{4}$ coefficient also depends on the share of sales to the domestic market, $\eta_{d}$, and $\beta_{4}$ falls further (becomes more negative) as export markets shrink and the domestic market is relatively more important.

There is a second way that the financial crisis can show up, however, and that is through the credit constraints themselves, i.e. the coefficients $\beta_{2}>0$ and $\beta_{3}<0$ of the interest payment and interest payment times export indicator. These coefficients in (37) reflect the credit constraints defined by (19), and it can be confirmed that both coefficients are falling in the interest rate. There is an offsetting effect on $\beta_{3}$, however, and that is through a rising share in the domestic market, $\eta_{d}$, which increases $\beta_{3}$ (moving it towards zero). The intuition here is that if exporters look more like domestic firms by increasing sales in the home market, then the bank will not impose as large of an "extra" credit constraint on the exporters. So the expected change in $\beta_{3}$ is ambiguous in theory, and we will evaluate it empirically by including a year indicator interacted with the interest payment times export indicator.

The results from these specifications are shown in Table 4. Columns (1) and (2) are a single regression, which includes both types of year interactions: the interactions with the export indicator in column (1), and the interaction with interest payments times the export indicator in column (2). The coefficients on the year $\times$ export interaction in column (1) are negative in all years (omitting 2000), but not significantly so until 2008 , when a very large value of $-184,579$ is obtained. Revenue is measured in thousands of US\$, so this coefficient indicates a drop in revenue of $\$ 185$ million for the typical exporting firm. That is much too large taken on its own, because the typical exporting firm has revenue of $\$ 24$ million over the entire sample (Table 1) and $\$ 41$ million in 2008. But this apparent drop in revenue is offset by the positive coefficients on the year $\times$ export $\times$ interest payment interactions in column (2), especially in 2008. We argued above that contracting foreign markets could lead to a positive coefficient on this interaction as the extra credit constraint on exporters is relaxed (because they look more like domestic firms), as we find strongly for 2008. But we believe that there is enough collinearity between the two types of year interactions in this regression that we may not be accurately measuring the effects of each one. 
Accordingly, we simplify by considering only the year $\times$ export interactions, as shown in column (3). ${ }^{28}$ In that case we find a negative coefficient in only one year, 2008 , of $-8,046$, indicating a drop in export revenue of $\$ 8$ million for the typical exporting firm. That represents about one-fifth of average revenue for exporters in 2008, which is our estimate of the impact of the financial crisis in that year. Note, however, that this estimate combines any increase in the interest rate with the drop in foreign market share, so we have not identified a pure effect of credit constraints. Also, the drop in revenue of one-fifth holds fixed the interest paid by firms; it could equally well be the case that loans and interest payments rise, which would offset some of this drop in revenue.

A final set of estimates reported in Table 4 keeps the year $\times$ exporter interactions, in column (4), and adds the additional year $\times$ exporter $\times$ foreign firm interactions, in column (5). Here we are interested in seeing how the financial crisis impacted foreign exporting firms versus non-foreign exporters. Our estimates in column (4) show that revenue for non-foreign exporters is reduced by $\$ 15.3$ million, or about two-fifths of those firms' average revenue in 2008 . In contrast, foreign exporters seem not to be affected by the credit constraint. ${ }^{29}$ The finding that non-foreign exporters were hit more by the crisis is consistent, once again, with the idea that multinational firms can raise internal finance from their parent company or affiliates to avoid the negative shock of credit constraints during the crisis.

\subsection{Fixed Costs and Collateral}

So far our estimates in Tables 3 and 4 abstract from the role of fixed costs and collateral. But as seen from (37), firms with higher fixed costs are expected to have lower revenue, via the coefficients $\beta_{0}<0$ and $\beta_{1}<0$. This effect arises because the bank loan covers both fixed costs and variable costs, so higher fixed costs reduce the funds to finance production. In addition to fixed costs, collateral also enters the estimating equation as a substitute for interest payments, as seen in in (36). Since $\beta_{2}>0$, collateral is positively associated with revenue, but with $\beta_{3}<0$, that effect is smaller for exporters.

We follow Manova (2008) by using the firm's tangible assets as a measure of collateral. When

\footnotetext{
${ }^{28}$ When instead we use only the year $\times$ export $\times$ interest payment interactions (not reported), we find that the coefficients are positive for all years after 2000, but no longer show the abrupt increase in 2008 that we find on column (2) of Table 4.

${ }^{29}$ Notice that the positive coefficients on the year $\times$ export $\times$ foreign firm interactions at the bottom of column (5) are offset by the negative coefficient of $-24,239$ on the export $\times$ foreign firm interaction, so the net impact on foreign firms is small in most years.
} 
tangible assets are entered as a level, the results are quite erratic. One reason for this might be that we do not have estimates of the default probability that multiplies collateral in (36), so that our collateral variable is measured with error. Rather than use the level of tangible assets, we instead measure them as a percentage of total assets, which leads to more stable results.

Table 5 reports the 2SLS estimates with fixed costs and collateral. In all regressions, firm's "overhead costs" are used as a measure of firm's fixed costs. ${ }^{30}$ Columns (1) and (2) use the firmspecific random effects without and with year-specific fixed effects, column (3) adds the industryspecific fixed effects, and column (4) also includes the interactions between the export indicator and industry-specific fixed effects. Most of the results are consistent with our theoretical predictions. Firms with higher overhead costs are associated with lower revenue, whereas firms with more collateral, as measured by tangible assets, have higher revenue.

When interacting these terms with the export indicator, tangible assets raises revenue slightly less for exporters, as expected from our model. We also expected that higher overhead costs would lower revenue somewhat more for exporters, but that is not the case in the estimation. On the contrary, the positive coefficient on overhead cost $\times$ export indicator just offsets the negative coefficient on overhead cost itself, so it appears that this measure of fixed costs has no impact at all on revenue for exporting firms. Admittedly, using overhead costs as a measure for fixed costs is subject to error, and perhaps that error is particularly severe for exporters.

\subsection{Selection and Alternative Specifications}

Tables 3-5 use the export indicator itself and interacted with other variables, but that variable is itself endogenous. To control for this, we introduce a selection equation that estimates the probability of a firm to export based on TFP and other structural variables. We then experiment using this predicted probability as an alternative to the export indicator.

In particular, we adopt the Probit estimation for the industrial export cutoff productivity:

$$
\text { Export }_{j t}=\left\{\begin{array}{l}
0 \text { if } V_{j t} \equiv x_{j t}-\underline{\mathrm{x}}_{e j t} \leq 0 \\
1 \text { if } V_{j t} \equiv x_{j t}-\underline{\mathrm{x}}_{e j t}>0
\end{array},\right.
$$

where $V_{j t}$ denotes a latent variable faced by firm $j$. Its distribution is the distribution of firm's TFP shifted to the left by the export cutoff productivity. We model this cutoff productivity as

\footnotetext{
${ }^{30}$ In the accounting definition, overhead costs refer to an ongoing expenses of operating a business that cannot be immediately associated with the products or services being offered. They include all costs on the income statement except for direct labor, direct materials \& direct expenses. Thus, overhead costs include accounting fees, advertising, depreciation, insurance, interest, legal fees, rent, repairs, supplies, taxes, telephone bills, travel and utilities costs.
} 
depending on the logarithm of firm's tangible assets $\ln T a n g_{j t}$, a foreign indicator $F O R_{j t}$, year indicators $D_{t}$ and interactions between the logarithm of tangible assets and year indicator. Thus, the latent variable $V_{j t}$ depends on these variables as well as TFP $x_{j t}$ :

$$
V_{j t}=\alpha_{0}+\alpha_{1} x_{j t}+\alpha_{2} \ln \operatorname{Tang}_{j t}+\alpha_{3} F_{O R}+\sum_{t=1}^{9} \alpha_{4 t} D_{t}+\sum_{t=1}^{9} \alpha_{5 t} D_{t} \times \ln \operatorname{Tang}_{j t}+\epsilon_{j t}
$$

where $\epsilon_{j t}$ is normally distributed. We can estimate the selection function by the Probit model:

$$
\begin{aligned}
\operatorname{Pr}\left(\text { Export }_{j t}\right. & =1)=\operatorname{Pr}\left(V_{j t}>0\right) \\
& =\Phi\left(\alpha_{0}+\alpha_{1} x_{j t}+\alpha_{2} \ln \text { Tang }_{j t}+\alpha_{3} \text { FOR }_{j t}+\sum_{t=1}^{9} \alpha_{4 t} D_{t}+\sum_{t=1}^{9} \alpha_{5 t} D_{t} \times \ln \text { Tang }_{j t}\right),
\end{aligned}
$$

where $\Phi($.$) is the cumulative density function of the normal distribution. We use the predicted$ export probabilities from this regression to replace the export indicator.

Table 6 reports the estimation results for the selection equation (40) using the probit model over the entire sample. We see that firms with higher TFP have a higher probability of exporting. In addition, firms with higher tangible assets are more likely to export, which is consistent with our theoretical results: having greater collateral will relax the cash flow constraint, especially for exporters. Foreign firms are also more likely to export, which is consistent with the idea that they are able to access external finance from their parent company. Interestingly, the included year indicators after 2000 are negative and rise in absolute value, which suggests that some timedependent variables not captured explicitly in the model (e.g., Renminbi appreciation after 2005) reduced the probability of firm's exporting. Finally, the interaction between the year indicators and tangible assets have very small negative coefficients in 2002-2005, but positive coefficients in 2006-2008, indicating that in the later years the role of tangible assets in relaxing the cash-flow constraint for exporters became more important. One explanation for this result from our model is that the probability of default increased in later years, in which case collateral become more important in (34).

While Table 6 gives a summary of the estimation of the Probit model for the entire sample, we re-estimated that equation by 2-digit industries, and use the estimated probability of exporting to replace the export indicator in our basic regression. The results are shown in Table 7 . The magnitude of the coefficients in each column are close to their counterparts in Table 3. In particular, firms with higher interest payment generate larger revenue, though the interest payment has smaller 
effect on revenue for exporters than for purely domestic firms. These results confirm that the endogeneity of the export decision was not biasing our earlier results.

As a second specification test, we consider breaking up exports into their mode of transport, as done by Amiti and Weinstein (2009). Our theory suggests that exporters are more constrained than domestic firms due, in part, to the longer time needed for export shipments. In reality, firms would have many types of shipments: by air, by sea, by truck, and by their combination. Usually sea shipment is the slowest and expected to have a longer time-lag on export payment. It is reasonable to suspect that if a firm relies more on sea shipment, it would then face more stringent credit constraints.

To test this hypothesis, we merged the Chinese firm-level trade data, which have detailed information on types of shipments, with Chinese firm-level production data. The time span of firm-level trade data is from 2000 to 2006, so it ends two years earlier than that of the production data. In addition, while we know which firms are exporters in the production data, there are many cases in which such firms cannot be merged with any record in the trade data. These firms are dropped, thereby reducing the sample further. To see the impacts of these sample reductions, we first use the firm-level production data alone to run the basic regression over 2000-2006 without merging with the trade data, which is reported in column (1) in Table 8. The sample of 1,117,267 observations in 2000-2008, used in Table 3, is reduced to a sample of 742,234 observations due to the omitted years 2007-2008. The regression in column (1), Table 8, carries the same message as Table 3: higher interest payments lead to higher revenue, though the impact is smaller for exporters.

Columns (2)-(5) of Table 8 report the results when the trade data are merged with the production data, causing further reduction of the sample. Column (2) has the same qualitative features as column (1), indicating limited impacts of dataset merge and loss of observations. Columns (3)-(5) report the estimates for different groups of firms of different shares of sea shipments. Comparing these different groups of firms (i.e., firms with sea shipment share $>50 \%,>95 \%$, and $>99 \%$ ), we see that firms with larger share of sea shipments tend to be more credit constrained, as indicated by the rising coefficients of the interest paymentxexport interactions (from 77.46 to 91.66 to 94.79 ). These findings are consistent with our hypothesis that exporters are more credit constrained due to the longer time needed for export shipments. 


\section{Conclusions}

In this paper, we have asked why firms will face credit constraints on their domestic sales and exports. We rely on the idea that firms must obtain working capital prior to production and that their productivity is private information. From the revelation principle, the bank can do no better than to offer loan and interest schedule that lead the firms to truthfully reveal this information. We argue that such incentive-compatible schedules will lead to credit constraints on the firms. The reason for this is that a firm that is not credit constrained would suffer only a second-order loss in profits by producing slightly less and borrowing less, but would have a first-order reduction in interest payments. Thus, such a firm would never truthfully reveal its productivity and produce at the first-best.

We have built into the model three reasons why export sales differ from domestic sales: due to a longer time-lag in exports between production and sales; due to a greater risk in exports; and due to additional fixed costs of exports. Our results show that the first of these reasons - the time needed for the loan - is most important in determining the credit constraints. This reason leads banks to impose a more stringent credit constraint on exporters, for both their exports and domestic sales, than on purely domestic firms. The more stringent credit constraint reduces both the intensive margin and the extensive margin of exports. The second reason, greater risk, enters due to the project risk of a firm not being paid or the default risk of the firm not repaying the bank. The risk also affects the credit extended by banks, but in different directions. We find that greater project risk in exports leads firms to optimally hold back on foreign sales, while the bank correspondingly reduces its loans and interest payments. In contrast, greater default risk by exporters leads to higher expected interest payments. Extra fixed costs further reduce the extensive margin of exports when the cash flow constraint is binding, but higher expected collateral held by exporters offsets this constraint and raises the extensive margin.

Our theoretical result that the exports and domestic sales of an exporting firm should face the same credit constraint corresponds most closely to the empirical finding of Behrens, Corcos and Mion (2010) for Belgium, who show that financial variables impact both types of sales equally within a firm. This contrasts to the empirical findings of Amiti and Weinstein (2009) for Japan, who show that the health of the main bank has a five-times greater impact on firm-level exports than domestic sales. One reason for this difference is that Amiti and Weinstein (2009) are arguably 
capturing the "trade finance" activities of these banks, targeted specifically at exports, whereas our model and empirical work deals with working-capital loans in general, as noted above.

We note that one limitation of our model is that it is static, whereas other theoretical literature focuses on the dynamic characteristics of credit constraints. Clementi and Hopenhayn (2006) characterize incentive-compatible credit constraints in a dynamic model, and show how such constraints affect firm's growth and survival. In this setting, a firm's credit constraint is relaxed when it increases its cash flow. Midrigan and Xu (2009) take a model of this type and apply it to plant-level data for Colombia and South Korea. Gross and Verani (2010) show how the firm revenue function used in Clementi and Hopenhayn (2006) can arise from a Melitz-style model, and drawing on Verani (2010), solve for the dynamics of domestic and exporting firms. None of these papers, however, introduce the distinctions between domestic firms and exporters - in the time-lag of shipments and default risk - that we use here. We anticipate that our results would apply in some form to these dynamic models, too, but that is beyond the scope of this paper.

Several other extensions merit special consideration. One of them is to endogenize the internal finance via multinational corporation a là Antràs et al. (2009). Another possible extension is to consider outward foreign direct investment (FDI) into the model in the sense that firms with higher productivity would perform outward FDI in addition to exports. A third would be to measure the welfare costs of the credit constraints derived here, as done by Midrigan and Xu (2009) for plants in Colombia and South Korea. Indeed, the credit constraints we have identified could explain part of the deadweight losses in Chinese manufacturing identified by Hsieh and Klenow (2009). These are all interesting topics to explore in future research. 


\section{References}

[1] Antràs, Pol, Mihir Desai, and C. Fritz Foley (2009), "FDI Flows and Multinational Firm Activity," Quarterly Journal of Economics 124 (3), pp. 1171-1219.

[2] Amiti, Mary, and David Weinstein (2009), "Exports and Financial Shocks, " NBER Working Paper, No. 15556.

[3] Baron, David P. and Myerson, Roger B. (1982), "Regulating a Monopolist with Unknown Costs," Econometrica, 50(4), pp. 911-930.

[4] Beck, Thorsten (2002), "Financial development and international trade: is there a link?" Journal of International Economics 57, pp. 107-131.

[5] Behrens, Kristian, Corcos, Gregory and Mion, Giordano (2010), "Trade Crisis? What Trade Crisis?" NBB Working Paper No. 195.

[6] Bolton, Partrick and David S. Scharfstein (1990), "A Theory of Predation Based on Agency Problems in Financial Contracting," American Economic Review 80 (1), pp. 93-106.

[7] Brandt, Loren, Johannes van Biesebroeck, and Yifan Zhang (2009), "Creative Accounting or Creative Destruction? Firm-Level Productivity Growth in Chinese Manufacturing," NBER Working Paper No. 15152.

[8] Buch, Claudia, Iris Kesternich, Alexander Lipponer, and Monika Schnitzer (2008), "Real versus Financial Barriers to Multinational Activity," mimeo, University of Tuebingen.

[9] Cai, Hongbin and Qiao Liu (2009),"Competition and Corporate Tax Avoidance: Evidence from Chinese Industrial Firms," Economic Journal, forthcoming.

[10] Chaney, Thomas (2005), "Liquidity Constrained Exporters", University of Chicago.

[11] Chiang, Alpha (2000) Elements of Dynamic Optimization. Waveland Press.

[12] Chor, Davin and Kalina Manova (2010) "Off the Cliff and Back? Credit Conditions and International Trade during the Global Financial Crisis," NBER Working Paper No. 16174.

[13] Claessens, Stijn and Tzioumis, Konstantinos (2006), "Measuring Firms' Access to Finance," mimeo., World Bank and Brooking conference paper.

[14] Clementi, Gian Luca and Hugo A. Hopenhayn (2006), "A Theory of Financing Constraints and Firm Dynamics," Quarterly Journal of Economics 121(1), pp. 229-265.

[15] Egger, Peter and Christian Keuschnigg (2011) "Access to Credit and Comparative Advantage," ETH Zuerich and University of St. Gallen.

[16] Greenaway, David, Alessandra Guariglia, and Richard Kneller (2007), "Financial Factors and Exporting Decisions," Journal of International Economics 73, pp. 377-395.

[17] Gross, Till and Stéphane Verani (2010), "A Theory of Firm Dynamics and International Trade," University of California, Sanata Barbara.

[18] Harrison, Ann E. and Margaret S. McMillan (2003), "Does Direct Foreign Investment Affect Domestic Credit Constraints?" Journal of International Economics 61, pp.73-100.

[19] Héricourt, Jérôme and Sandra Poncet (2009), "FDI and credit constraints: firm level evidence in China", Economic Systems 33 (1), pp. 1-21.

[20] Holz, Carsten (2004), "China's Statistical System in Transition: Challenges, Data Problems, and Institutional Innovations," Review of Income and Wealth 50(3), pp. 381-409. 
[21] Hsieh, Chang-Tai, and Peter Klenow (2009), "Misallocation an d Manufacturing TFP in China and India," Quarterly Journal of Economics 124 (4), pp. 1403-448.

[22] Kletzer, Kenneth and Pranab Bardhan (1987), "Credit Markets and Patterns of International Trade", Journal of Development Economics 27 (1-2), pp. 57-70.

[23] Keller, Wolfgang and Stephen Yeaple (2009), "Multinational Enterprises, International Trade, and Technology Diffusion: A Firm-level Analysis of the Productivity Effects of Foreign Competition in the United States," Review of Economics and Statistics, 2009, 91(4), pp. 821-831.

[24] Levchenko, Andrei A., Logan T. Lewis and Linda L. Tesar (2010), "The Collapse of International Trade During the 2008-2009 Crisis: In Search of the Smoking Gun," NBER Working Papers 16006.

[25] Levinsohn, James and Amil Petrin (2003), "Estimating Production Functions Using Inputs to Control for Unobservable," Review of Economic Studies 70(2), pp. 317-341.

[26] Lin, Justin, Fang Cai, and Zhou Li (2004), The China Miracle, The Chinese University of Hong Kong.

[27] Manova, Kalina (2008), "Credit Constraints, Heterogeneous Firms and International Trade," NBER Working Paper No. 14531.

[28] Manova, Kalina, Shang-Jin Wei, and Zhiwei Zhang (2009), "Firm Exports and Multinational Activity under Credit Constraints," Stanford University.

[29] Matsuyama, Kiminori (2005), "Credit Market Imperfections and Patterns of International Trade and Capital Flows," Journal of the European Economic Association, 3(2-3), 714-723.

[30] Melitz, Marc (2003), "The Impact of Trade on Intra-industry Reallocations and Aggregate Industry Productivity," Econometrica 71(6), pp. 1695-1725.

[31] Midrigan, Virgiliu and Daniel Yi Xu (2009), "Finance and misallocation: Evidence from plantlevel data," NBER Working Papers 15647.

[32] Murtazashvili, Irina \& Wooldridge, Jeffrey M. (2008) "Fixed effects instrumental variables estimation in correlated random coefficient panel data models," Journal of Econometrics, 142(1), 539-552.

[33] Muûls, Mirabelle (2008), "Exporters and Credit Constraints: A Firm-level Approach," National Bank of Belgium working paper number 139.

[34] Olley, Steven and Ariel Pakes (1996), "The Dynamics of Productivity in the Telecommunications Equipment Industry," Econometrica 64(6), pp. 1263-1297.

[35] Poncet, Sandra, Walter Steingress and Hylke Vandenbussche (2009), "Credit Allocation in China: Firm-Level Evidence", MET 17(2), pp. 3-7.

[36] Qiu, Larry D. (1999), "Credit Rationing and Patterns of New Product Trade," Journal of Economic Integration, 14(1), pp. 75-95.

[37] Verani, Stéphane (2010), "Aggregate Consequences of Firm-Level Financing Constraints," University of California, Santa Barbara.

[38] Yu, Miaojie (2010), "Processing Trade, Firm Productivity, and Tariff Reductions: Evidence from Chinese Products," CCER Working Paper, No. E201006, Peking University. 
Table 1: Basic Statistics for Key Variables (2000-2008)

\begin{tabular}{lll}
\hline \hline Variables & Mean & Std.Dev. \\
\hline Firm's Revenue $(\$ 1,000)$ & 12,660 & 136,812 \\
Domestic Firm's Revenue $(\$ 1,000)$ & 8,157 & 60,615 \\
Export Firm's Revenue $(\$ 1,000)$ & 23,916 & 236,948 \\
Foreign Firm's Revenue $(\$ 1,000)$ & 21,163 & 160,212 \\
Firm's Interest Payment $(\$ 1,000)$ & 138.5 & 1,657 \\
Domestic Firm's Interest Payment $(\$ 1,000)$ & 83.98 & 802.6 \\
Export Firm's Interest Payment $(\$ 1,000)$ & 274.9 & 2,825 \\
Foreign Firm's Interest Payment $(\$ 1,000)$ & 133.4 & 1,669 \\
Log of TFP (Olley-Pakes) & 4.211 & 1.135 \\
Log of Firm's Real Capital & 8.30 & 1.68 \\
Log of Capital-Labor Ratio & 3.56 & 1.32 \\
Firm's Revenue-Cost Ratio & 1.05 & 8.67 \\
Interest Payment $\times$ Export Indicator & 78.56 & 1,515 \\
Export Value $(\$ 1,000)$ & 2,478 & 69,160 \\
Export Value $(\$ 1,000)$ Conditional on Exporting & 8,673 & 129,174 \\
Export Indicator & .285 & .451 \\
Estimated Export Probability & .285 & .199 \\
State-owned Firm Dummy & .035 & .184 \\
Foreign Firm Indicator (exclusive H/M/T) & .104 & .306 \\
Foreign Firm Indicator (inclusive H/M/T) & .211 & .408 \\
\hline
\end{tabular}

Notes: There are 1,158,359 observations in the sample. Firms revenue and interest payment are converted to dollar using the exchange rate (1 dollar=8.05 Renminbi on average). SOEs dummy equals one for pure state-owned enterprises, stated-owned joint venture enterprises, state-owned and collective joint venture enterprises, and stateown limited corporation firms, and zero otherwise. There are 41,092 SOEs in the sample, which are dropped in the regressions. All foreign (i.e.,multinational) firms are defined exclusive of those originating in Hong Kong, Macau, or Taiwan $(\mathrm{H} / \mathrm{M} / \mathrm{T})$, except in the final row of the table. 
Table 2: Total Factor Productivity of Chinese Plants (2000-2007)

\begin{tabular}{|c|c|c|c|c|}
\hline Chinese Industrial Classfication (2-digit) & $\begin{array}{l}\text { Labor } \\
\text { coeff. }\end{array}$ & $\begin{array}{l}\text { Capital } \\
\text { coeff. }\end{array}$ & $\begin{array}{l}\text { Log of } \\
\text { TFP for } \\
\text { Domestic }\end{array}$ & $\begin{array}{l}\log \text { of } \\
\text { TFP for } \\
\text { Exporter }\end{array}$ \\
\hline Processing of Foods (13) & .447 & .286 & 4.419 & 4.394 \\
\hline Manufacturing of Foods (14) & .444 & .309 & 3.980 & 4.027 \\
\hline Manufacture of Beverages (15) & .474 & .422 & 2.942 & 3.072 \\
\hline Manufacture of Tobacco (16) & .416 & .669 & .667 & 1.315 \\
\hline Manufacture of Textile (17) & .437 & .203 & 4.760 & 4.863 \\
\hline Manufacture of Apparel, Footwear \& Caps (18) & .508 & .184 & 4.527 & 4.448 \\
\hline Manufacture of Leather, Fur, \& Feather (19) & .474 & .350 & 3.569 & 3.408 \\
\hline $\begin{array}{l}\text { Processing of Timber, Manufacture of Wood, } \\
\text { Bamboo, Rattan, Palm \& Straw Products }(20)\end{array}$ & .446 & .130 & 5.333 & 5.421 \\
\hline Manufacture of Furniture (21) & .563 & .231 & 4.051 & 3.951 \\
\hline Manufacture of Paper \& Paper Products (22) & .473 & .276 & 4.005 & 4.260 \\
\hline Printing, Reproduction of Recording Media (23) & .413 & .195 & 4.874 & 5.091 \\
\hline $\begin{array}{l}\text { Manufacture of Articles For Culture, Education } \\
\& \text { Sport Activities }(24)\end{array}$ & .490 & .168 & 4.813 & 4.773 \\
\hline Processing of Petroleum, Coking, \&Fuel (25) & .252 & .282 & 5.213 & 6.188 \\
\hline Manufacture of Raw Chemical Materials (26) & .313 & .346 & 4.356 & 4.575 \\
\hline Manufacture of Medicines (27) & .411 & .208 & 5.265 & 5.548 \\
\hline Manufacture of Chemical Fibers (28) & .382 & .304 & 4.391 & 4.700 \\
\hline Manufacture of Rubber (29) & .377 & .308 & 4.242 & 4.303 \\
\hline Manufacture of Plastics (30) & .421 & .239 & 4.600 & 4.595 \\
\hline Manufacture of Non-metallic Mineral goods (31) & .321 & .422 & 3.577 & 3.778 \\
\hline Smelting \& Pressing of Ferrous Metals (32) & .464 & .308 & 4.140 & 4.504 \\
\hline Smelting \& Pressing of Non-ferrous Metals (33) & .362 & .260 & 4.975 & 5.210 \\
\hline Manufacture of Metal Products (34) & .420 & .277 & 4.370 & 4.314 \\
\hline Manufacture of General Purpose Machinery (35) & .404 & .282 & 4.386 & 4.459 \\
\hline Manufacture of Special Purpose Machinery (36) & .406 & .404 & 3.443 & 3.434 \\
\hline Manufacture of Transport Equipment (37) & .466 & .396 & 3.214 & 3.248 \\
\hline Electrical Machinery \& Equipment (39) & .453 & .405 & 3.141 & 4.902 \\
\hline Computers \& Other Electronic Equipment (40) & .495 & .192 & 5.074 & 3.658 \\
\hline $\begin{array}{l}\text { Manufacture of Measuring Instruments \& Ma- } \\
\text { chinery for Cultural Activity \& Office Work (41) }\end{array}$ & .408 & .411 & 3.426 & 3.597 \\
\hline Manufacture of Artwork (42) & .460 & .347 & 3.597 & 3.492 \\
\hline All industries & .399 & .278 & 4.258 & 4.196 \\
\hline
\end{tabular}

Notes: We do not report standard errors for each coefficient to save space, which are available upon request. 
Table 3: 2SLS Estimates (2000-2008) without Fixed Costs or Collateral

\begin{tabular}{|c|c|c|c|c|c|}
\hline Regressand: Firm's Revenue & $(1)$ & $(2)$ & $(3)$ & $(4)$ & $(5)$ \\
\hline & OLS & $2 \mathrm{SLS}$ & $2 \mathrm{SLS}$ & $2 \mathrm{SLS}$ & 2SLS \\
\hline Interest Payment & $\begin{array}{l}60.91^{* *} \\
(32.46)\end{array}$ & $\begin{array}{l}217.5^{* *} \\
(17.30)\end{array}$ & $\begin{array}{l}219.7^{* *} \\
(17.44)\end{array}$ & $\begin{array}{l}217.5^{* *} \\
(38.24)\end{array}$ & $\begin{array}{l}217.7^{* *} \\
(37.51)\end{array}$ \\
\hline Interest Payment $\times$ Foreign Indicator & $\begin{array}{c}-32.07^{* *} \\
(-5.95)\end{array}$ & $\begin{array}{l}-41.20 \\
(-1.13)\end{array}$ & $\begin{array}{l}-43.70 \\
(-1.20)\end{array}$ & $\begin{array}{c}-41.20^{* *} \\
(-4.20)\end{array}$ & $\begin{array}{c}-41.26^{* *} \\
(-4.12)\end{array}$ \\
\hline Interest Payment $\times$ Export Indicator & $\begin{array}{c}14.64^{* *} \\
(3.74)\end{array}$ & $\begin{array}{c}-69.98^{* *} \\
(-4.48)\end{array}$ & $\begin{array}{c}-72.77^{* *} \\
(-4.55)\end{array}$ & $\begin{array}{c}-69.98^{* *} \\
(-11.95)\end{array}$ & $\begin{array}{c}-70.02^{* *} \\
(-11.70)\end{array}$ \\
\hline $\begin{array}{l}\text { Interest Payment } \times \text { Export Indicator } \\
\times \text { Foreign Indicator }\end{array}$ & $\begin{array}{l}-1.31 \\
(-.15)\end{array}$ & $\begin{array}{c}95.98^{* *} \\
(2.17)\end{array}$ & $\begin{array}{c}97.93^{* *} \\
(2.21)\end{array}$ & $\begin{array}{c}95.98^{* *} \\
(9.39)\end{array}$ & $\begin{array}{c}93.55^{* *} \\
(8.97)\end{array}$ \\
\hline Export Indicator & $\begin{array}{l}231.8 \\
(.30)\end{array}$ & $\begin{array}{c}-10,860^{* *} \\
(-4.32)\end{array}$ & $\begin{array}{c}-764.3 \\
(-.60)\end{array}$ & $\begin{array}{c}-10,860^{* *} \\
(-16.07)\end{array}$ & $\begin{array}{c}-13,036^{* *} \\
(-17.59)\end{array}$ \\
\hline Export Indicator $\times$ Foreign Indicator & $\begin{array}{c}4,277^{* *} \\
(3.38)\end{array}$ & $\begin{array}{l}387.9 \\
(.06)\end{array}$ & $\begin{array}{l}-1,698 \\
(-.26)\end{array}$ & $\begin{array}{l}387.9 \\
(.22)\end{array}$ & $\begin{array}{l}186.6 \\
(.10)\end{array}$ \\
\hline Foreign Indicator & $\begin{array}{l}8,072^{* *} \\
(12.97)\end{array}$ & $\begin{array}{l}-3,775 \\
(-.86)\end{array}$ & $\begin{array}{l}-2,635 \\
(-.60)\end{array}$ & $\begin{array}{c}-3,775^{* *} \\
(-2.51)\end{array}$ & $\begin{array}{c}-3770^{* *} \\
(-2.40)\end{array}$ \\
\hline $\begin{array}{l}\text { Kleibergen-Paap rk LM } \chi^{2} \text { statistic } \\
\text { Kleibergen-Paap rk Wald F statistic }\end{array}$ & - & $\begin{array}{l}327.2^{\dagger} \\
14.78^{\dagger}\end{array}$ & $\begin{array}{l}326.8^{\dagger} \\
14.43^{\dagger}\end{array}$ & - & - \\
\hline Year-Specific Fixed Effects & Yes & Yes & Yes & Yes & Yes \\
\hline Industry-Specific Fixed Effects & Yes & Yes & Yes & Yes & Yes \\
\hline Export Indicator $\times$ Ind. Fixed Effects & No & No & Yes & No & No \\
\hline Firm-Specific Random Effects & No & No & No & Yes & Yes \\
\hline Number of Observations & $1,121,223$ & $1,117,267$ & $1,117,267$ & $1,117,267$ & $1,068,169$ \\
\hline \multicolumn{6}{|c|}{ First-Stage Regressions } \\
\hline IV1: $T F P_{i t}^{O P}$ & - & $\begin{array}{c}.139 * * \\
(7.37) \\
{[30.56]}\end{array}$ & $\begin{array}{l}.135^{* *} \\
(7.54) \\
{[31.95]}\end{array}$ & $\begin{array}{c}.139 * * \\
(20.82) \\
-\end{array}$ & $\begin{array}{c}.139^{* *} \\
(20.29) \\
-\end{array}$ \\
\hline IV2: $T F P_{i t}^{O P} \times$ Foreign Indicator & - & $\begin{array}{l}.279^{* *} \\
(4.66) \\
{[21.35]}\end{array}$ & $\begin{array}{l}.280^{* *} \\
(4.69) \\
{[21.67]}\end{array}$ & $\begin{array}{c}.279^{* *} \\
(39.35) \\
-\end{array}$ & $\begin{array}{c}.279 * * \\
(38.51) \\
-\end{array}$ \\
\hline IV3: $T F P_{i t}^{O P} \times$ Export Indicator & - & $\begin{array}{c}.726^{* *} \\
(2.36) \\
{[32.82]}\end{array}$ & $\begin{array}{c}.003^{* *} \\
(6.29) \\
{[36.48]}\end{array}$ & $\begin{array}{c}.726^{* *} \\
(65.39) \\
-\end{array}$ & $\begin{array}{c}.731^{* *} \\
(63.77) \\
-\end{array}$ \\
\hline $\begin{array}{l}\text { IV4: } T F P_{i t}^{O P} \times \text { Foreign Indicator } \\
\times \text { Export Indicator }\end{array}$ & - & $\begin{array}{l}.750 * * \\
(7.52) \\
{[16.52]} \\
\end{array}$ & $\begin{array}{l}.752^{* *} \\
(7.56) \\
{[20.85]}\end{array}$ & $\begin{array}{c}.750 * * \\
(89.91) \\
-\end{array}$ & $\begin{array}{c}.768^{* *} \\
(89.28) \\
- \\
\end{array}$ \\
\hline
\end{tabular}

Notes: Robust t-values corrected for clustering at the firm level in parentheses. *(**) indicates significance at the 10(5) percent level. $\dagger$ indicates significance of p-value at the 1 percent level. Excluded F statistic in the first stage are reported in square brackets. Column (5) drops 49,098 observations with pure exporters which exports equal total sales.

In the first-stage regressions, IV1 reports the coefficient of TFP (Olley-Pakes) level in the estimation using interest payment as the regressand. Similarly, IV2 reports the coefficient of the product between TFP level and foreign firm (FOR)'s dummy in the estimation using the product of interest payment and FOR as the regressand. IV3 reports the coefficient of the product between TFP level and export dummy in the estimation using the product of interest payment and export dummy as the regressand. Finally, IV4 reports the coefficient of the product among TFP level, export dummy, foreign firm's dummy in the estimation using the product of interest payment, foreign dummy, and export dummy as the regressand. 
Table 4: 2SLS Estimates (2000-2008) using Export Interactions by Year

\begin{tabular}{|c|c|c|c|c|c|}
\hline Regressand: Firm's Revenue & $(1)$ & $(2)$ & $(3)$ & $(4)$ & $(5)$ \\
\hline \multirow[t]{3}{*}{ Interaction with: } & Export & Export & Export & Export & Export \\
\hline & Indicator & Indicator & Indicator & Indicator & $\times$ Foreign \\
\hline & & $\times$ Interest & & & Indicator \\
\hline \multirow[t]{2}{*}{ Interest Payment } & \multicolumn{2}{|c|}{$210.7^{* *}$} & $210.7^{* *}$ & \multicolumn{2}{|c|}{$210.7^{* *}$} \\
\hline & \multicolumn{2}{|c|}{$(17.59)$} & $(17.59)$ & \multicolumn{2}{|c|}{$(17.59)$} \\
\hline \multirow[t]{2}{*}{ Interest Payment $\times$ Foreign Indicator } & \multicolumn{2}{|c|}{-39.13} & -39.13 & \multicolumn{2}{|c|}{-39.13} \\
\hline & \multicolumn{2}{|c|}{$(-1.09)$} & $(-1.09)$ & \multicolumn{2}{|c|}{$(-1.09)$} \\
\hline \multirow[t]{2}{*}{ Interest Payment $\times$ Export Indicator } & \multicolumn{2}{|c|}{$-153.5^{* *}$} & $-66.14^{* *}$ & \multirow{2}{*}{\multicolumn{2}{|c|}{$\begin{array}{c}-66.26^{* *} \\
(-4.35)\end{array}$}} \\
\hline & \multicolumn{2}{|c|}{$(-4.39)$} & $(-4.34)$ & & \\
\hline \multirow{2}{*}{$\begin{array}{l}\text { Interest Payment } \times \text { Export Indicator } \\
\times \text { Foreign Indicator }\end{array}$} & \multicolumn{2}{|c|}{$92.51^{* *}$} & $94.74^{* *}$ & \\
\hline & $(2$. & & $(2.17)$ & \multicolumn{2}{|c|}{$\begin{array}{c}95.24^{* *} \\
(2.18)\end{array}$} \\
\hline \multirow[t]{2}{*}{ Export Indicator } & \multicolumn{2}{|c|}{7.980} & $-7,737^{* *}$ & \multicolumn{2}{|c|}{$-2,926$} \\
\hline & \multicolumn{2}{|c|}{$(1.20)$} & $(-2.54)$ & \multicolumn{2}{|c|}{$(-1.10)$} \\
\hline \multirow[t]{2}{*}{ Export Indicator $\times$ Foreign Indicator } & \multirow{2}{*}{\multicolumn{2}{|c|}{$\begin{array}{c}10,563 \\
(1.06)\end{array}$}} & $-1,478$ & \multirow{2}{*}{\multicolumn{2}{|c|}{$\begin{array}{c}-24,239^{* *} \\
(-2.11)\end{array}$}} \\
\hline & & & $(-.23)$ & & \\
\hline \multirow[t]{2}{*}{ Foreign Indicator } & & & $-1,658$ & & \\
\hline & & & $(-.38)$ & & \\
\hline Interaction for 2001 & $-4,809$ & 22.55 & 646.3 & -698.1 & 5,886 \\
\hline & $(-.68)$ & $(.62)$ & $(.21)$ & $(-.28)$ & $(.52)$ \\
\hline Interaction for 2002 & $-5,102$ & 31.45 & 2,699 & $-1,157$ & $17,999^{*}$ \\
\hline & $(-.71)$ & $(.84)$ & $(.98)$ & $(-.51)$ & $(1.80)$ \\
\hline Interaction for 2003 & $-10,382$ & $85.16^{* *}$ & $7,555^{* *}$ & 2,230 & $25,045^{* *}$ \\
\hline & $(-1.53)$ & $(2.26)$ & $(2.96)$ & $(1.10)$ & $(2.67)$ \\
\hline Interaction for 2004 & $-12,118^{*}$ & $97.11^{* *}$ & $7,806^{* *}$ & 2,030 & $26,510^{* *}$ \\
\hline & $(-1.81)$ & $(2.57)$ & $(3.01)$ & $(.99)$ & $(2.82)$ \\
\hline Interaction for 2005 & $-16,345^{* *}$ & $104.3^{* *}$ & $5,049^{* *}$ & 726.0 & $20,659^{* *}$ \\
\hline & $(-2.13)$ & $(2.43)$ & $(1.96)$ & $(.35)$ & $(2.21)$ \\
\hline Interaction for 2006 & $-16,678^{* *}$ & $95.51^{* *}$ & 3,523 & $-1,207$ & $22,343^{* *}$ \\
\hline & $(-2.22)$ & $(2.44)$ & $(1.37)$ & $(-.57)$ & $(2.42)$ \\
\hline Interaction for 2007 & $-16,986^{* *}$ & $80.20^{* *}$ & -208.4 & $-4,733^{* *}$ & $21,574^{* *}$ \\
\hline & $(-2.22)$ & $(2.17)$ & $(-.08)$ & $(-2.05)$ & $(2.33)$ \\
\hline Interaction for 2008 & $-184,579 * *$ & $429.0^{* *}$ & $-8,046^{*}$ & $-15,341^{* *}$ & $32,649^{* *}$ \\
\hline & $(-2.01)$ & $(2.20)$ & $(1.93)$ & $(-3.25)$ & $(3.16)$ \\
\hline Year-Specific Fixed Effects & $\mathrm{Y}$ & & Yes & & \\
\hline Number of Observations & 1,117 & 267 & $1,117,267$ & $1,11^{\prime}$ & 267 \\
\hline
\end{tabular}

Notes: Robust t-values corrected for clustering at the firm level in parentheses. ${ }^{*}(*)$ indicates significance at the 10(5) percent level. The regression in columns (1) and (2) includes both export indicator $\times$ year and export indicator $\times$ interest payment $\times$ year interactions. Column (3) includes only export indicator $\times$ year interactions. The regression in columns (4) and (5) includes both export indicator $\times$ year and export indicator $\times$ foreign indicator $\times$ year interactions. 
Table 5: 2SLS Estimates (2000-2008) with Fixed Costs and Collateral

\begin{tabular}{|c|c|c|c|c|}
\hline Regressand: Firm's Revenue & $(1)$ & $(2)$ & $(3)$ & $(4)$ \\
\hline Interest Payment & $\begin{array}{c}1,113^{* *} \\
(5.78)\end{array}$ & $\begin{array}{c}1,116^{* *} \\
(5.81)\end{array}$ & $\begin{array}{c}1,569^{* *} \\
(4.07)\end{array}$ & $\begin{array}{c}1,688^{* *} \\
(3.84)\end{array}$ \\
\hline Interest Payment $\times$ Foreign Indicator & $\begin{array}{c}-345.8^{* *} \\
(-4.29)\end{array}$ & $\begin{array}{c}-350.8^{* *} \\
(-4.34)\end{array}$ & $\begin{array}{c}-523.7^{* *} \\
(-3.33)\end{array}$ & $\begin{array}{c}-571.9^{* *} \\
(-3.22)\end{array}$ \\
\hline Interest Payment $\times$ Export Indicator & $\begin{array}{c}-943.3^{* *} \\
(-4.89)\end{array}$ & $\begin{array}{c}-947.1^{* *} \\
(-4.92)\end{array}$ & $\begin{array}{c}-1,382^{* *} \\
(-3.58)\end{array}$ & $\begin{array}{c}-1,514^{* *} \\
(-3.44)\end{array}$ \\
\hline $\begin{array}{l}\text { Interest Payment } \times \text { Export Indicator } \\
\times \text { Foreign Indicator }\end{array}$ & $\begin{array}{c}404.5^{* *} \\
(4.97)\end{array}$ & $\begin{array}{c}408.4^{* *} \\
(5.01)\end{array}$ & $\begin{array}{c}570.3^{* *} \\
(3.67)\end{array}$ & $\begin{array}{c}623.6^{* *} \\
(3.50)\end{array}$ \\
\hline Export Indicator & $\begin{array}{c}12,531 \\
(.45)\end{array}$ & $\begin{array}{l}7,484 \\
(.27)\end{array}$ & $\begin{array}{c}25,022 \\
(.62)\end{array}$ & $\begin{array}{c}79,650^{* *} \\
(3.14)\end{array}$ \\
\hline Export Indicator $\times$ Foreign Indicator & $\begin{array}{c}-60,251^{* *} \\
(-4.40)\end{array}$ & $\begin{array}{c}-60,772^{* *} \\
(-4.43)\end{array}$ & $\begin{array}{c}-78,610^{* *} \\
(-3.27)\end{array}$ & $\begin{array}{c}-84,133^{* *} \\
(-3.24)\end{array}$ \\
\hline Foreign Indicator & $\begin{array}{c}57,002^{* *} \\
(4.31)\end{array}$ & $\begin{array}{c}57,412^{* *} \\
(4.34)\end{array}$ & $\begin{array}{c}74,158^{* *} \\
(3.19)\end{array}$ & $\begin{array}{c}27,522 \\
(.63)\end{array}$ \\
\hline Overhead Cost & $\begin{array}{c}-212.2^{* *} \\
(-5.21)\end{array}$ & $\begin{array}{c}-212.4^{* *} \\
(-5.24)\end{array}$ & $\begin{array}{c}-307.1^{* *} \\
(-3.74)\end{array}$ & $\begin{array}{c}-332.3^{* *} \\
(-3.59)\end{array}$ \\
\hline Overhead Cost $\times$ Export Indicator & $\begin{array}{c}207.0^{* *} \\
(5.08)\end{array}$ & $\begin{array}{c}207.3^{* *} \\
(5.11)\end{array}$ & $\begin{array}{c}300.6^{* *} \\
(3.67)\end{array}$ & $\begin{array}{c}326.7^{* *} \\
(3.53)\end{array}$ \\
\hline Tangible Asset & $\begin{array}{c}392.2^{* *} \\
(2.65)\end{array}$ & $\begin{array}{c}772.5^{* *} \\
(4.42)\end{array}$ & $\begin{array}{c}126.0^{* *} \\
(3.74)\end{array}$ & $\begin{array}{c}135.0^{* *} \\
(3.61)\end{array}$ \\
\hline Tangible Asset $\times$ Export Indicator & $\begin{array}{c}-60.09 \\
(-.22)\end{array}$ & $\begin{array}{c}-15.66 \\
(-.06)\end{array}$ & $\begin{array}{c}-32.13 \\
(-.81)\end{array}$ & $\begin{array}{c}-39.53 \\
(-.92)\end{array}$ \\
\hline Year-Specific Fixed Effects & No & Yes & Yes & Yes \\
\hline Industry-Specific Fixed Effects & No & No & Yes & Yes \\
\hline Export Dummy $\times$ Ind. Fixed Effects & No & No & No & Yes \\
\hline Firm-Specific Random Effects & Yes & Yes & Yes & Yes \\
\hline Number of Observations & $1,062,171$ & $1,062,171$ & $1,062,171$ & $1,062,171$ \\
\hline
\end{tabular}

Notes: Robust t-values corrected for clustering at the firm level in parentheses. * $(* *)$ indicates significance at the 10(5) percent level. Excluded F statistic in the first stage are reported in square brackets. Here firm's tangible asset is measured in percentage by using its tangible assets over its total assets times 100 . 
Table 6: The Probit Estimates of Firm's Selection Effects (2000-2008)

\begin{tabular}{lccc}
\hline \hline Variables & Coefficient & Variables & Coefficient \\
\hline TFP Level & $.019^{* *}$ & Foreign Indicator & $.975^{* *}$ \\
& $(4.73)$ & $(240.1)$ \\
Log of Tangible Assets & $.129^{* *}$ & Tangible Assets $\times 2001$ & - \\
& $(54.75)$ & Interaction & \\
Year Indicator in 2001 & $-1.91^{* *}$ & Tangible Assets $\times 2002$ & $-.011^{* *}$ \\
& $(-45.02)$ & Interaction & $(-1.97)$ \\
Year Indicator in 2002 & $-1.79^{* *}$ & Tangible Assets $\times 2003$ & -.004 \\
& $(-44.00)$ & Interaction & $(-.92)$ \\
Year Indicator in 2003 & $-1.87^{* *}$ & Tangible Assets $\times 2004$ & -.0005 \\
& $(-64.77)$ & Interaction & $(-.11)$ \\
Year Indicator in 2004 & $-1.86^{* *}$ & Tangible Assets $\times 2005$ & -.005 \\
& $(-78.22)$ & Interaction & $(-1.14)$ \\
Year Indicator in 2005 & $-1.88^{* *}$ & Tangible Assets $\times 2006$ & $.015^{* *}$ \\
& $(-78.63)$ & Interaction & $(3.22)$ \\
Year Indicator in 2006 & $-2.14^{* *}$ & Tangible Assets $\times 2007$ & $.026^{* *}$ \\
& $(-93.41)$ & Interaction & $(5.64)$ \\
Year Indicator in 2007 & $-2.37^{* *}$ & Tangible Assets $\times 2008$ & $.013^{* *}$ \\
& $(-107.8)$ & Interaction & $(2.74)$ \\
Year Indicator in 2008 & $-2.23^{* *}$ & & \\
& $(-82.82)$ & & \\
\hline
\end{tabular}

Notes: Robust t-values corrected for clustering at the firm level in parentheses. *(**) indicates significance at the 10(5) percent level. The selection model is equ. (40) in the text. The regressand is firm's export dummy. There are 1,103,270 observations in the regressions. The interaction term for each year in the table means the product of firm's logarithm of tangible assets and the year indicator. 
Table 7: Alternative 2SLS Estimates, using Estimated Export Probability (2000-2008)

\begin{tabular}{|c|c|c|c|c|}
\hline Regressand: Firm's Revenue & $(1)$ & $(2)$ & $(3)$ & $(4)$ \\
\hline \multirow[t]{2}{*}{ Interest Payment } & $201.6^{* *}$ & $206.6^{* *}$ & $201.7^{* *}$ & $260.6^{* *}$ \\
\hline & $(12.23)$ & $(11.73)$ & $(31.49)$ & $(25.67)$ \\
\hline \multirow[t]{2}{*}{ Interest Payment $\times$ Foreign Indicator } & $105.1^{* *}$ & $101.9^{* *}$ & $101.9^{* *}$ & $79.99^{* *}$ \\
\hline & $(2.23)$ & $(2.14)$ & $(9.84)$ & $(6.29)$ \\
\hline \multirow[t]{2}{*}{ Interest Payment $\times$ Export Probability } & $-103.2^{* *}$ & $-99.64^{* *}$ & $-99.64^{* *}$ & $-187.7^{* *}$ \\
\hline & $(-2.62)$ & $(-2.35)$ & $(-5.79)$ & $(-7.97)$ \\
\hline \multirow{2}{*}{$\begin{array}{l}\text { Interest Payment } \times \text { Export Probability } \\
\times \text { Foreign Indicator }\end{array}$} & -138.8 & -139.1 & $-139.1^{* *}$ & $-88.56^{* *}$ \\
\hline & $(-1.61)$ & $(-1.58)$ & $(-6.08)$ & $(-3.15)$ \\
\hline \multirow[t]{2}{*}{ Export Probability } & $11,798^{* *}$ & $-25,816^{* *}$ & $-25,816^{* *}$ & $-18,556$ \\
\hline & $(4.00)$ & $(-6.77)$ & $(-13.69)$ & $(-1.18)$ \\
\hline \multirow[t]{2}{*}{ Export Probability $\times$ Foreign Indicator } & $41,623^{* *}$ & $45,986^{* *}$ & $45,986^{* *}$ & $38,631^{* *}$ \\
\hline & $(3.14)$ & $(3.42)$ & $(10.89)$ & $(7.71)$ \\
\hline \multirow[t]{2}{*}{ Foreign Indicator } & $-27,313^{* *}$ & $-28,837 * *$ & $-25,816^{* *}$ & $-25,212^{* *}$ \\
\hline & $(-3.31)$ & $(-3.46)$ & $(-13.69)$ & $(-10.28)$ \\
\hline \multirow{2}{*}{$\begin{array}{l}\text { Kleibergen-Paap rk LM } \chi^{2} \text { statistic } \\
\text { Kleibergen-Paap rk Wald F statistic }\end{array}$} & $311.3^{\dagger}$ & $287.6^{\dagger}$ & - & - \\
\hline & 5.45 & 4.84 & & \\
\hline Industry-Specific Fixed Effects & No & Yes & Yes & No \\
\hline Year-Specific Fixed Effects & Yes & Yes & Yes & Yes \\
\hline Export Indicator $\times$ Ind. Fixed Effects & No & No & No & Yes \\
\hline \multirow{2}{*}{$\begin{array}{l}\text { Firm-Specific Random Effects } \\
\text { Observations }\end{array}$} & No & No & Yes & Yes \\
\hline & $1,117,186$ & $1,117,186$ & $1,117,186$ & $1,117,186$ \\
\hline \multicolumn{5}{|c|}{ First-Stage Regressions } \\
\hline \multirow[t]{3}{*}{ IV1: $T F P_{i t}^{O P}$} & $.278^{* *}$ & $.275^{* *}$ & $.275^{* *}$ & $.139 * *$ \\
\hline & $(3.54)$ & $(3.42)$ & $(25.83)$ & $(13.18)$ \\
\hline & {$[30.84]$} & [27.11] & - & - \\
\hline \multirow[t]{3}{*}{ IV2: $T F P_{i t}^{O P} \times$ Foreign Indicator } & $.353^{* *}$ & $.358^{* *}$ & $.358^{* *}$ & $.357^{* *}$ \\
\hline & $(2.76)$ & $(2.80)$ & $(32.85)$ & $(32.78)$ \\
\hline & {$[20.05]$} & {$[22.62]$} & - & - \\
\hline \multirow[t]{3}{*}{ IV3: $T F P_{i t}^{O P} \times$ Export Probability } & $.237 * *$ & $.226^{*}$ & $.226^{* *}$ & $.277^{* *}$ \\
\hline & $(2.00)$ & $(1.93)$ & $(23.67)$ & $(29.12)$ \\
\hline & {$[39.17]$} & {$[33.35]$} & - & - \\
\hline \multirow{3}{*}{$\begin{array}{l}\text { IV4: } T F P_{i t}^{O P} \times \text { Foreign Indicator } \\
\times \text { Export Probability }\end{array}$} & $.750 * *$ & $.744^{* *}$ & $.744^{* *}$ & $.74^{* *}$ \\
\hline & $(3.73)$ & $(3.70)$ & $(67.72)$ & $(67.43)$ \\
\hline & {$[16.89]$} & {$[24.26]$} & - & - \\
\hline
\end{tabular}

Notes: Robust t-values corrected for clustering at the firm level in parentheses. ${ }^{*}(*)$ indicates significance at the 10(5) percent level. Excluded F statistic in the first stage are reported in brackets. †indicates significance of p-value at the 1 percent level. As introduced in the text, we use the predicted value in the Probit model to serve as the firms' export probability.

In the first-stage regressions, IV1 reports the coefficient of TFP (Olley-Pakes) level in the estimation using interest payment as the regressand. Similarly, IV2 reports the coefficient of the product between TFP level and foreign firm (FOR)'s dummy in the estimation using the product of interest payment and FOR as the regressand. IV 3 reports the coefficient of the product between TFP level and export dummy in the estimation using the product of interest payment and export dummy as the regressand. Finally, IV4 reports the coefficient of the product among TFP level, export dummy, foreign firm's dummy in the estimation using the product of interest payment, foreign dummy, and export dummy as the regressand. 
Table 8: 2SLS Estimates (2000-2006) by Extent of Sea Shipments

\begin{tabular}{|c|c|c|c|c|c|}
\hline \multirow{3}{*}{$\begin{array}{l}\text { Regressand: Firm's Revenue } \\
\text { Types of Shipments: }\end{array}$} & Without Merge & \multicolumn{4}{|c|}{ "Merged with Trade Data (2000-2006) } \\
\hline & All Firms & All Firms & $>50 \%$ & $>95 \%$ & $>99 \%$ \\
\hline & $(1)$ & $(2)$ & $(3)$ & $(4)$ & $(5)$ \\
\hline \multirow[t]{2}{*}{ Interest Payment } & $199.3^{* *}$ & $193.4^{* *}$ & $191.2^{* *}$ & $191.3^{* *}$ & $191.1^{* *}$ \\
\hline & (41.84) & $(58.48)$ & $(66.92)$ & $(68.61)$ & (69.84) \\
\hline \multirow[t]{2}{*}{ Interest Payment $\times$ Foreign Indicator } & 2.94 & $20.06^{* *}$ & 6.76 & 6.90 & 6.87 \\
\hline & $(.28)$ & $(2.46)$ & $(1.03)$ & $(1.08)$ & $(1.10)$ \\
\hline \multirow[t]{2}{*}{ Interest Payment $\times$ Export Indicator } & $-51.30 * *$ & $-74.09^{* *}$ & $-77.46^{* *}$ & $-91.65^{* *}$ & $-94.79 * *$ \\
\hline & $(-10.66)$ & $(-20.82)$ & $(-24.90)$ & $(-30.36)$ & $(-32.07)$ \\
\hline \multirow{2}{*}{$\begin{array}{l}\text { Interest Payment } \times \text { Export Indicator } \\
\times \text { Foreign Indicator }\end{array}$} & $80.28^{* *}$ & $36.51^{* *}$ & $15.91^{* *}$ & $22.78^{* *}$ & $24.99 * *$ \\
\hline & $(7.31)$ & $(4.30)$ & $(2.30)$ & $(3.39)$ & $(3.79)$ \\
\hline \multirow[t]{2}{*}{ Export Indicator } & $-6,734^{* *}$ & $-8,583^{* *}$ & $-3,757^{* *}$ & $-1,376^{* *}$ & -954.8 \\
\hline & $(13.95)$ & $(-7.71)$ & $(-6.06)$ & $(-2.14)$ & $(-1.41)$ \\
\hline \multirow[t]{2}{*}{ Export Indicator $\times$ Foreign Indicator } & $-2,182$ & $5,938 * *$ & $9,014^{* *}$ & $6,120 * *$ & $5,419^{* *}$ \\
\hline & $(-1.34)$ & $(4.13)$ & $(6.83)$ & $(4.54)$ & $(3.88)$ \\
\hline \multirow[t]{2}{*}{ Foreign Indicator } & $-7,177^{* *}$ & $-3,383^{* *}$ & $-7,013^{* *}$ & $-6,965^{* *}$ & $-6,940^{* *}$ \\
\hline & $(-5.00)$ & $(-5.73)$ & $(-7.70)$ & $(-7.84)$ & $(-7.95)$ \\
\hline Year-Specific Fixed Effects & Yes & Yes & Yes & Yes & Yes \\
\hline Industry-Specific Fixed Effects & Yes & Yes & Yes & Yes & Yes \\
\hline Firm-Specific Random Effects & Yes & Yes & Yes & Yes & Yes \\
\hline Number of Observations & 742,434 & 563,195 & 552,937 & 546,448 & 540,856 \\
\hline
\end{tabular}

Notes: Robust t-values corrected for clustering at the firm level in parentheses. * $(* *)$ indicates significance at the 10(5) percent level. In Column (2), we drop those exporting firms which are not matched with trade data due to lack of common identifiers in both firm-level production data and trade data. Columns (3)-(5) reports the samples of share of firm's exports by sea over its total exports are higher than 50\%, 95\%, and 99\%, respectively. 


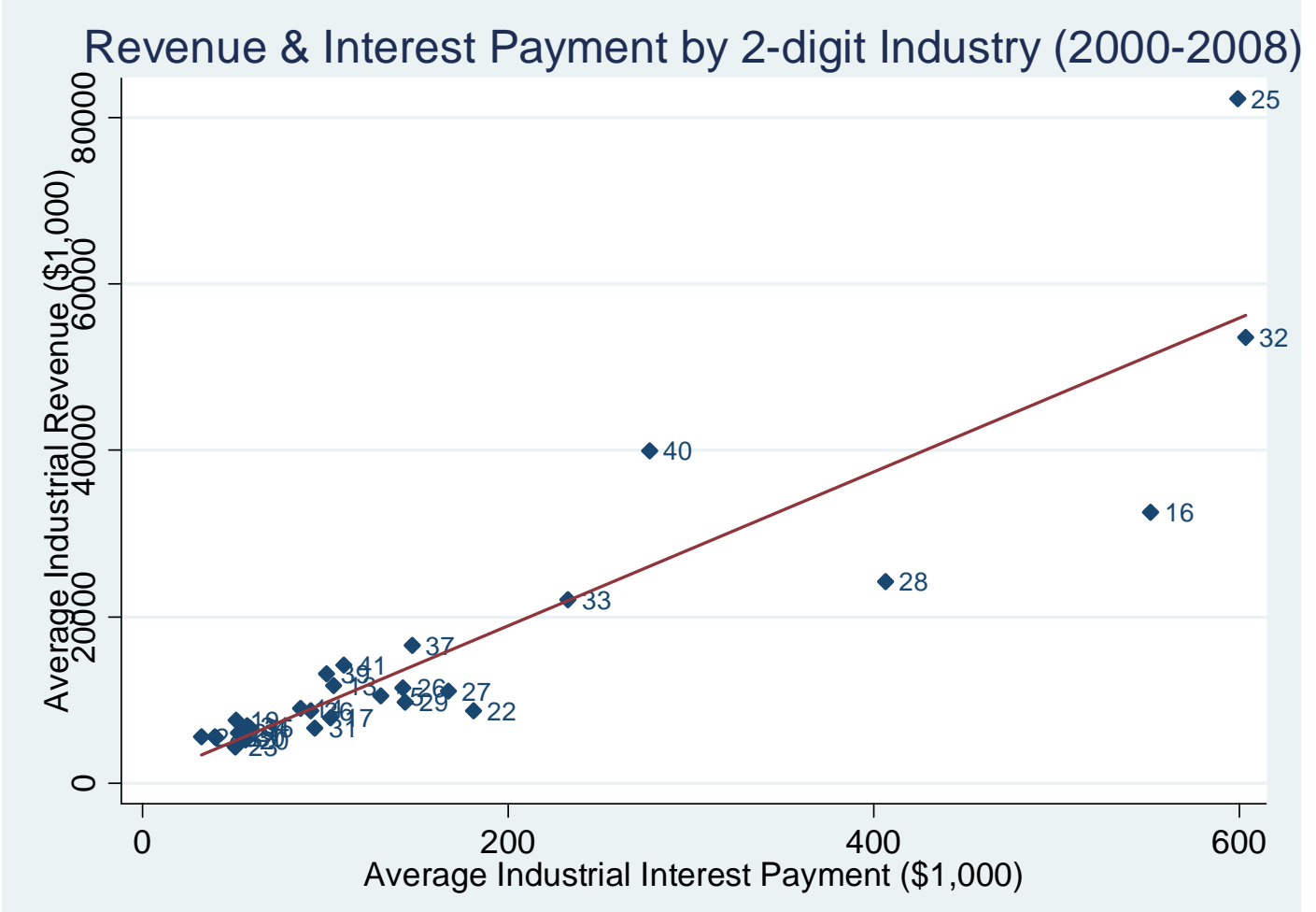

Notes: The average industrial revenue and interest pament are calculated over years 2000-2008 by 2-digit level Chinese manfuacturing sectors. Table 2 provides the detailed description for numbers of each sector.

Figure 1: Chinese Firm's Revenue and Interest Payment by 2-digit Industry 


\section{Appendix}

\section{A Solving the Bank's Problem}

\section{A.1 The Loan Schedules}

The constraints to the banks's problem involve these control variables as well as their derivatives, $M_{e}^{d \prime}(x)$ and $M_{d}^{\prime}(x)$. Incorporating constraints in the control variables and their derivatives is relatively straighforward using the Euler-Lagrange equation of the calculus of variations (Chiang, 2000 , p. 137). We simplify the notation by denoting $\Phi_{d}\left(x, M_{d}(x)\right)$ as $\Phi_{d}, \Phi_{e}^{d}\left(x, M_{e}^{d}(x)\right)$ as $\Phi_{e}^{d}$ and $\Phi_{e}^{e}\left(x, M_{e}^{e}(x)\right)$ as $\Phi_{e}^{e}$. We define the Lagrangian function using the integrand of the bank's objective and the incentive-compatibility constraint, for $x \in\left[\underline{\mathrm{x}}_{d}, \underline{\mathrm{x}}_{e}\right]$ as:

$$
\begin{aligned}
£ & =\left(\rho_{d} I_{d}(x)-i \tau_{d} M_{d}(x)-\left(1-\rho_{d}\right)\left(M_{d}(x)-K_{d}\right)\right) f(x) \\
& +\lambda(x)\left(\left(\Phi_{d}+\delta\left(1-\rho_{d}\right)-1\right) M_{d}^{\prime}(x) / \delta-\rho_{d} I_{d}^{\prime}(x)\right) .
\end{aligned}
$$

Likewise, for exporting firms the Lagrangian function is defined for $x \in\left[\underline{\mathrm{x}}_{e}, \infty\right)$ as,

$$
\begin{aligned}
£ & =\left(\rho_{e} I_{e}(x)-\left(1-\rho_{e}\right)\left(M_{e}(x)-K_{e}\right)-i \tau_{d} M_{e}^{d}(x)-i \tau_{e} M_{e}^{e}(x)\right) f(x) \\
& +\lambda(x)\left(\left(\Phi_{e}^{d}+\delta\left(1-\rho_{e}\right)-1\right) M_{e}^{\prime}(x) / \delta-\rho_{e} I_{e}^{\prime}(x)\right) .
\end{aligned}
$$

We can simplify the bank's problem for the exporting firms by explicitly solving for the relationship between the loans $M_{e}^{d}(x)$ and $M_{e}^{e}(x)$, using the equality of marginal revenues in (10). As explained in the text, this solution is:

$$
\frac{M_{e}^{e}(x) / \delta-C_{e}}{M_{e}^{d}(x) / \delta-C_{d}}=\frac{\eta_{e}}{\eta_{d}} .
$$

Substituting this relation and (16) into (42), the Lagrangian function for the bank for $x \in\left[\underline{\mathrm{x}}_{e}, \infty\right)$ becomes,

$$
\begin{aligned}
£ & =\left(\rho_{e} I_{e}(x)+\left(1-\rho_{e}\right) K_{e}-\left(1-\rho_{e}+i \tau_{d}\right) M_{e}^{d}(x)-\left(1-\rho_{e}+i \tau_{e}\right)\left(\frac{\eta_{e}}{\eta_{d}}\left(M_{e}^{d}(x)-C_{d} \delta\right)+C_{e} \delta\right)\right) f(x) \\
& +\lambda(x)\left(\left(\Phi_{e}^{d}+\delta\left(1-\rho_{e}\right)-1\right) \frac{M_{e}^{d \prime}(x)}{\delta \eta_{d}}-\rho_{e} I_{e}^{\prime}(x)\right) .
\end{aligned}
$$

According to the Euler-Lagrange equation, the solution to (17) must satisfy the conditions $\frac{\partial \mathscr{E}}{\partial I}-\frac{d}{d x} \frac{\partial \mathscr{E}}{\partial I^{\prime}}=0$ and $\frac{\partial \mathscr{E}}{\partial M}-\frac{d}{d x} \frac{\partial \mathscr{E}}{\partial M^{\prime}}=0$. For $\mathrm{x} \in\left[\underline{\mathrm{x}}_{d}, \underline{\mathrm{x}}_{e}\right]$ these conditions are:

$$
\begin{array}{r}
f(x)+\lambda^{\prime}(x)=0, \\
\left(1-\rho_{d}+i \tau_{d}\right) f(x)-\lambda(x) \frac{\partial \Phi_{d}}{\partial M_{d}} \frac{M_{d}^{\prime}(x)}{\delta}+\left(\Phi_{d}+\delta\left(1-\rho_{d}\right)-1\right) \frac{\lambda^{\prime}(x)}{\delta}+\frac{\lambda(x)}{\delta} \frac{d \Phi_{d}}{d x}=0 .
\end{array}
$$

Since $\Phi_{d}=\Phi_{d}\left(x, M_{d}(x)\right)$ then $\frac{d \Phi_{d}}{d x}=\frac{\partial \Phi_{d}}{\partial x}+\frac{\partial \Phi_{d}}{\partial M_{d}} M_{d}^{\prime}(x)$, and it follows that the second equation is simplified as,

$$
\left(1-\rho_{d}+i \tau_{d}\right) f(x)+\left(\Phi_{d}+\delta\left(1-\rho_{d}\right)-1\right) \frac{\lambda^{\prime}(x)}{\delta}+\frac{\lambda(x)}{\delta} \frac{\partial \Phi_{d}}{\partial x}=0,
$$

Using a similar simplification, for $x \in\left[\underline{\mathrm{x}}_{e}, \infty\right)$ we obtain the conditions:

$$
\begin{aligned}
f(x)+\lambda^{\prime}(x) & =0, \\
\left(\frac{1-\rho_{e}}{\eta_{d}}+i \tau_{d}+i \tau_{e} \frac{\eta_{e}}{\eta_{d}}\right) f(x)+\left(\Phi_{e}^{d}+\delta\left(1-\rho_{e}\right)-1\right) \frac{\lambda^{\prime}(x)}{\delta \eta_{d}}+\frac{\lambda(x)}{\delta \eta_{d}} \frac{\partial \Phi_{e}^{d}}{\partial x} & =0 .
\end{aligned}
$$


We impose a tranversality condition on the bank's problem such that $\lambda(\infty)=0$. Then the optimality condition for exporting firms (45) indicates that $\lambda(x)=\lambda\left(\underline{\mathrm{x}}_{e}\right)-\int_{\underline{x}_{e}}^{x} f(x) d x=$ $\lambda\left(\underline{\mathrm{x}}_{e}\right)-\left(F(x)-F\left(\underline{\mathrm{x}}_{e}\right)\right)$, where $F(x)$ is the cumulative density function of $f(x)$. Combined with the transversality condition, it readily follows that $\lambda\left(\underline{\mathrm{x}}_{e}\right)=1-F\left(\underline{\mathrm{x}}_{e}\right)$ and consequently $\lambda(x)=1-F(x)$ for $x \in\left[\underline{\mathrm{x}}_{e}, \infty\right)$. Using $\lambda\left(\underline{\mathrm{x}}_{e}\right)=1-F\left(\underline{\mathrm{x}}_{e}\right)$ and the optimality condition for domestic firms (43), we also obtain $\lambda(x)=1-F(x)$ for $x \in\left[\underline{\mathrm{x}}_{d}, \underline{\mathrm{x}}_{e}\right]$.

Substituting this solution for $\lambda(x)$ into (44) and (46), and noticing that $\partial \Phi_{d} / \partial x=\left(\frac{\sigma-1}{\sigma}\right) \Phi_{d} / x$ and $\partial \Phi_{e}^{d} / \partial x=\left(\frac{\sigma-1}{\sigma}\right) \Phi_{e}^{d} / x$, it follows that the solution for the credit constraints are as shown in (18).

\section{A.2 The Cutoff Productivity Levels}

Using the solutions for the domestic credit constraints $\bar{\Phi}_{d}$ together with the incentive-compatibility condition (6), we can re-write the expected interest payments as:

$$
\rho_{d} I_{d}(x)=\rho_{d} I_{d}\left(\underline{\mathrm{x}}_{d}\right)+\left(\bar{\Phi}_{d}+\delta\left(1-\rho_{d}\right)-1\right)\left(M_{d}(x)-M_{d}\left(\underline{\mathrm{x}}_{d}\right)\right) / \delta
$$

A similar expression can be obtained for $\rho_{e} I_{e}(x)$. Substituting these into the banks problem (17), it becomes,

$$
\begin{aligned}
& \max _{\underline{\underline{\mathbf{x}}}_{d}, \underline{\underline{x}}_{e}} \int_{\underline{\mathbf{x}}_{d}}^{\underline{\mathrm{x}}_{e}}\left[\begin{array}{c}
\rho_{d} I_{d}\left(\underline{\mathrm{x}}_{d}\right)+\left[\bar{\Phi}_{d}+\delta\left(1-\rho_{d}\right)-1\right]\left(M_{d}(x)-M_{d}\left(\underline{\mathrm{x}}_{d}\right)\right) / \delta \\
-i \tau_{d} M_{d}(x)-\left(1-\rho_{d}\right)\left(M_{d}(x)-K_{d}\right)
\end{array}\right] f(x) d x \\
& +\int_{\underline{\underline{x}}_{e}}^{\infty}\left[\begin{array}{c}
\rho_{e} I_{e}\left(\underline{\mathrm{x}}_{e}\right)+\left[\bar{\Phi}_{e}+\delta\left(1-\rho_{e}\right)-1\right]\left(M_{e}(x)-M_{e}\left(\underline{\mathrm{x}}_{e}\right)\right) / \delta \\
-i \tau_{d} M_{e}^{d}(x)-i \tau_{e} M_{e}^{e}(x)-\left(1-\rho_{e}\right)\left(M_{e}(x)-K_{e}\right)
\end{array}\right] f(x) d x .
\end{aligned}
$$

Solving this maximization problem requires taking first order derivative respect to $\underline{x}_{d}$ and $\underline{x}_{e}$. In order to do this, we shall first show some properties of the expected interest payments for marginal firms, $\rho_{d} I_{d}\left(\underline{\mathrm{x}}_{d}\right)$ and $\rho_{e} I_{e}\left(\underline{\mathrm{x}}_{e}\right)$. The domestic firm's expected profit is,

$$
E\left(\pi_{d}(x, x)\right)=\frac{\sigma}{\sigma-1}\left(M_{d}(x) / \delta-C_{d}\right) \bar{\Phi}_{d}-\rho_{d}\left(M_{d}(x)+I_{d}(x)\right)-\left(1-\rho_{d}\right) K_{d}-(1-\delta) \frac{M_{d}(x)}{\delta} .
$$

The first term, the expected revenue, is given by the product of total variable cost, $\left(M_{d}(x) / \delta-C_{d}\right)$, the ratio of marginal revenue to marginal cost, $\frac{\sigma}{\sigma-1} \bar{\Phi}_{d}$. Since $E\left(\pi_{d}(x, x)\right)$ is an increasing function in $x$, it follows that the zero-cutoff-profit condition for the domestic producer is:

$$
\rho_{d} I_{d}\left(\underline{\mathrm{x}}_{d}\right)=\frac{\bar{\Phi}_{d} \sigma}{\sigma-1}\left(M_{d}\left(\underline{\mathrm{x}}_{d}\right) / \delta-C_{d}\right)-\rho_{d} M_{d}\left(\underline{\mathrm{x}}_{d}\right)-\left(1-\rho_{d}\right) K_{d}-(1-\delta) \frac{M_{d}\left(\underline{\mathrm{x}}_{d}\right)}{\delta} .
$$

For the exporter, a similar argument shows that expected profits are:

$$
E\left(\pi_{e}(x, x)\right)=\frac{\bar{\Phi}_{e} \sigma}{\sigma-1}\left(M_{e}(x) / \delta-C_{d}-C_{e}\right)-\rho_{e}\left(M_{e}(x)+I_{e}(x)\right)-\left(1-\rho_{e}\right) K_{e}-(1-\delta) \frac{M_{e}(x)}{\delta} .
$$

The zero-cutoff-profit condition for the exporter is $E\left(\pi_{e}\left(\underline{\mathrm{x}}_{e}, \underline{\mathrm{x}}_{e}\right)\right)=E\left(\pi_{d}\left(\underline{\mathrm{x}}_{e}, \underline{\mathrm{x}}_{e}\right)\right)$. By using (49) and (51) evaluted at $x=\underline{\mathrm{x}}_{e}$, we obtain,

$$
\begin{aligned}
\rho_{e} I_{e}\left(\underline{\mathrm{x}}_{e}\right) & =\frac{\sigma \bar{\Phi}_{e}}{\sigma-1}\left(M_{e}\left(\underline{\mathrm{x}}_{e}\right) / \delta-C_{d}-C_{e}\right)-\rho_{e} M_{e}\left(\underline{\mathrm{x}}_{e}\right)-\left(1-\rho_{e}\right) K_{e}+\left(1-\rho_{d}\right) K_{d} \\
& -\frac{\sigma \bar{\Phi}_{d}}{\sigma-1}\left(M_{d}\left(\underline{\mathrm{x}}_{e}\right) / \delta-C_{d}\right)+\rho_{d} I_{d}\left(\underline{\mathrm{x}}_{d}\right)+\left(\bar{\Phi}_{d}-1+\delta\right) \frac{M_{d}\left(\underline{\mathrm{x}}_{e}\right)}{\delta} \\
& -\left(\bar{\Phi}_{d}+\delta\left(1-\rho_{d}\right)-1\right) \frac{M_{d}\left(\underline{\mathrm{x}}_{d}\right)}{\delta}-\frac{(1-\delta)}{\delta}\left(M_{e}\left(\underline{\mathrm{x}}_{e}\right)-M_{d}\left(\underline{\mathrm{x}}_{e}\right)\right)
\end{aligned}
$$


The two equations (50) and (52) imply that the bank can freely choose the cutoff productivity, $\underline{\mathrm{x}}_{d}$ and $\underline{\mathrm{x}}_{e}$, independently. Once the bank selects the the cutoff productivities, it can then set the associated interest payments for the cutoff firms according to (50) and (52). But from the latter equation, the interest payments $\rho_{e} I_{e}\left(\underline{\mathrm{x}}_{e}\right)$ will depend on the value of $\underline{\mathrm{x}}_{d}$, which appears on the right.

The first-order condition of (48) with respect to $\underline{x}_{d}$ is, taking into account that (52) includes terms related to $\underline{x}_{d}$, is

$$
\begin{aligned}
& \int_{\underline{\mathrm{x}}_{d}}^{\infty}\left(\rho_{d} \frac{d I_{d}\left(\underline{\mathrm{x}}_{d}\right)}{d \underline{\mathrm{x}}_{d}}-\left[\bar{\Phi}_{d}+\delta\left(1-\rho_{d}\right)-1\right] \frac{d M_{d}\left(\underline{\mathrm{x}}_{d}\right)}{d \underline{\mathrm{x}}_{d}} \frac{1}{\delta}\right) f(x) d x \\
& =\left[\rho_{d} I_{d}\left(\underline{\mathrm{x}}_{d}\right)-i \tau_{d} M_{d}\left(\underline{\mathrm{x}}_{d}\right)-\left(1-\rho_{d}\right)\left(M_{d}\left(\underline{\mathrm{x}}_{d}\right)-K_{d}\right)\right] f\left(\underline{\mathrm{x}}_{d}\right) .
\end{aligned}
$$

Notice that:

$$
\int_{\underline{x}_{d}}^{\infty}\left(\rho_{d} \frac{d I_{d}\left(\underline{\mathrm{x}}_{d}\right)}{d \underline{\mathrm{x}}_{d}}-\left[\bar{\Phi}_{d}+\delta\left(1-\rho_{d}\right)-1\right] \frac{d M_{d}\left(\underline{\mathrm{x}}_{d}\right)}{d \underline{\mathrm{x}}_{d}} \frac{1}{\delta}\right) f(x) d x=\bar{\Phi}_{d}\left(M_{d}\left(\underline{\mathrm{x}}_{d}\right) / \delta-C_{d}\right) \frac{f\left(\underline{\mathrm{x}}_{d}\right)}{\theta},
$$

where the equality holds since $\rho_{d} \frac{d I_{d}\left(\underline{\mathrm{x}}_{d}\right)}{d \underline{\mathrm{x}}_{d}}=\left(\frac{\sigma}{\sigma-1} \bar{\Phi}_{d}+\delta\left(1-\rho_{d}\right)-1\right) \frac{1}{\delta} \frac{d M_{d}\left(\underline{\mathrm{x}}_{d}\right)}{d \underline{\mathrm{x}}_{d}}$ from (50), $\frac{1-F\left(\underline{\mathrm{x}}_{d}\right)}{\underline{\mathrm{x}}_{d} f\left(\underline{x}_{d}\right)}=\frac{1}{\theta}$ under Pareto distribution and $\frac{d M_{d}\left(\underline{\mathrm{x}}_{d}\right)}{d \underline{\mathrm{x}}_{d}}=\frac{\sigma-1}{\underline{\mathrm{x}}_{d}}\left(M_{d}\left(\underline{\mathrm{x}}_{d}\right) / \delta-C_{d}\right) \delta$ from (20). Also notice from (50) that:

$$
\begin{aligned}
& {\left[\rho_{d} I_{d}\left(\underline{\mathrm{x}}_{d}\right)-i \tau_{d} M_{d}\left(\underline{\mathrm{x}}_{d}\right)-\left(1-\rho_{d}\right)\left(M_{d}\left(\underline{\mathrm{x}}_{d}\right)-K_{d}\right)\right] f\left(\underline{\mathrm{x}}_{d}\right)} \\
& =\left[\frac{\sigma \bar{\Phi}_{d}}{\sigma-1}\left(M_{d}\left(\underline{\mathrm{x}}_{d}\right) / \delta-C_{d}\right)-\left(1+i \tau_{d}\right) M_{d}\left(\underline{\mathrm{x}}_{d}\right)-(1-\delta) \frac{M_{d}\left(\underline{\mathrm{x}}_{d}\right)}{\delta}\right] f\left(\underline{\mathrm{x}}_{d}\right) .
\end{aligned}
$$

The first-order condition with respect to $\underline{x}_{d}$ is then solved as,

$$
M_{d}\left(\underline{\mathrm{x}}_{d}\right) / \delta-C_{d}=\left[\frac{\left(\frac{\sigma \theta}{\sigma-1}-1\right) \bar{\Phi}_{d}}{\theta\left(1+i \delta \tau_{d}\right)}-1\right]^{-1} \quad C_{d}=(\sigma-1) C_{d}
$$

where the second equality hold by substituting in $\bar{\Phi}_{d}$. We then have the loan for the cutoff producer as,

$$
M_{d}\left(\underline{\mathrm{x}}_{d}\right) / \delta=\sigma C_{d}
$$

Substituting this loan for the cutoff producer into (50), and we obtain the expected interest payment for the cutoff producer,

$$
\rho_{d} I_{d}\left(\underline{\mathrm{x}}_{d}\right)=\left[\bar{\Phi}_{d}+\delta\left(1-\rho_{d}\right)-1\right] \frac{M_{d}\left(\underline{\mathrm{x}}_{d}\right)}{\delta}-\left(1-\rho_{d}\right) K_{d}
$$

The interest payment schedule for firms with $\mathrm{x} \in\left[\underline{\mathrm{x}}_{d}, \underline{\mathrm{x}}_{e}\right]$ is then

$$
\rho_{d} I_{d}(x)=\left[\bar{\Phi}_{d}+\delta\left(1-\rho_{d}\right)-1\right] \frac{M_{d}(x)}{\delta}-\left(1-\rho_{d}\right) K_{d} \forall x \in\left[\underline{\mathrm{x}}_{d}, \underline{\mathrm{x}}_{e}\right] .
$$

The first-order condition with respect to $\underline{x}_{e}$ is slightly more complicated:

$$
\begin{aligned}
& \int_{\underline{\mathrm{x}}_{e}}^{\infty}\left(\rho_{e} \frac{d I_{e}\left(\underline{\mathrm{x}}_{e}\right)}{d \underline{\mathrm{x}}_{e}}-\left[\bar{\Phi}_{e}+\delta\left(1-\rho_{e}\right)-1\right] \frac{1}{\delta} \frac{d M_{e}\left(\underline{\mathrm{x}}_{e}\right)}{d \underline{\mathrm{x}}_{e}}\right) f(x) d x \\
& =\left(\left(\rho_{e} I_{e}\left(\underline{\mathrm{x}}_{e}\right)-i \tau_{d} M_{e}^{d}\left(\underline{\mathrm{x}}_{e}\right)-i \tau_{e} M_{e}^{e}\left(\underline{\mathrm{x}}_{e}\right)\right)-\left(\rho_{d} I_{d}\left(\underline{\mathrm{x}}_{e}\right)-i \tau_{d} M_{d}\left(\underline{\mathrm{x}}_{e}\right)\right)\right) f\left(\underline{\mathrm{x}}_{e}\right) \\
& -\left(\left(1-\rho_{e}\right)\left(M_{e}\left(\underline{\mathrm{x}}_{e}\right)-K_{e}\right)-\left(1-\rho_{d}\right)\left(M_{d}\left(\underline{\mathrm{x}}_{e}\right)-K_{d}\right)\right) f\left(\underline{\mathrm{x}}_{e}\right)
\end{aligned}
$$


Similar to the solution for $\underline{x}_{d}$, we notice that,

$$
\begin{aligned}
& \int_{\underline{x}_{e}}^{\infty}\left(\rho_{e} \frac{d I_{e}\left(\underline{\mathrm{x}}_{e}\right)}{d \underline{\mathrm{x}}_{e}}-\left[\bar{\Phi}_{e}+\delta\left(1-\rho_{e}\right)-1\right] \frac{d M_{e}\left(\underline{\mathrm{x}}_{e}\right)}{d \underline{\mathrm{x}}_{e}} \frac{1}{\delta}\right) f(x) d x \\
& =\left(\frac{\bar{\Phi}_{e}}{\theta}\left(M_{e}\left(\underline{\mathrm{x}}_{e}\right) / \delta-C_{d}-C_{e}\right)-\frac{\bar{\Phi}_{d}}{\theta}\left(M_{d}\left(\underline{\mathrm{x}}_{e}\right) / \delta-C_{d}\right)\right) f\left(\underline{\mathrm{x}}_{e}\right) \\
& =\left(\frac{\bar{\Phi}_{e}}{\theta}-\frac{\bar{\Phi}_{d}}{\theta}\left(\frac{\bar{\Phi}_{d}}{\bar{\Phi}_{e}}\right)^{-\sigma} \eta_{d}\right)\left(M_{e}\left(\underline{\mathrm{x}}_{e}\right) / \delta-C_{d}-C_{e}\right) f\left(\underline{\mathrm{x}}_{e}\right)
\end{aligned}
$$

where the first equality holds since,

$$
\rho_{e} \frac{d I_{e}\left(\underline{\mathrm{x}}_{e}\right)}{d \underline{\mathrm{x}}_{e}}=\left(\frac{\sigma \bar{\Phi}_{e}}{\sigma-1}+\delta\left(1-\rho_{e}\right)-1\right) \frac{1}{\delta} \frac{d M_{e}\left(\underline{\mathrm{x}}_{e}\right)}{d \underline{\mathrm{x}}_{e}}-\frac{\bar{\Phi}_{d}}{(\sigma-1) \delta} \frac{d M_{d}\left(\underline{\mathrm{x}}_{e}\right)}{d \underline{\mathrm{x}}_{e}}
$$

and $\frac{d M_{e}\left(\underline{\mathrm{x}}_{e}\right)}{d \underline{\mathrm{x}}_{e}}=\frac{(\sigma-1)}{\underline{\mathrm{x}}_{e}}\left(M_{e}\left(\underline{\mathrm{x}}_{e}\right) / \delta-C_{d}-C_{e}\right) \delta$. The second equality holds since

$$
\frac{M_{d}\left(\underline{\mathrm{x}}_{e}\right) / \delta-C_{d}}{M_{e}^{d}\left(\underline{\mathrm{x}}_{e}\right) / \delta-C_{d}}=\left(\frac{\bar{\Phi}_{d}}{\bar{\Phi}_{e}^{d}}\right)^{-\sigma},
$$

due to (20), and $\left(M_{e}^{d}\left(\underline{\mathrm{x}}_{e}\right) / \delta-C_{d}\right)=\eta_{d}\left(M_{e}\left(\underline{\mathrm{x}}_{e}\right) / \delta-C_{d}-C_{e}\right)$ due to (12). The right hand side of (57) can be rewriten as, ignoring $f\left(\underline{\mathrm{x}}_{e}\right)$,

$$
\begin{aligned}
& \left(\rho_{e} I_{e}\left(\underline{\mathrm{x}}_{e}\right)-i \tau_{d} M_{e}^{d}\left(\underline{\mathrm{x}}_{e}\right)-i \tau_{e} M_{e}^{e}\left(\underline{\mathrm{x}}_{e}\right)\right)-\left(\rho_{d} I_{d}\left(\underline{\mathrm{x}}_{e}\right)-i \tau_{d} M_{d}\left(\underline{\mathrm{x}}_{e}\right)\right) \\
& -\left(\left(1-\rho_{e}\right)\left(M_{e}\left(\underline{\mathrm{x}}_{e}\right)-K_{e}\right)-\left(1-\rho_{d}\right)\left(M_{d}\left(\underline{\mathrm{x}}_{e}\right)-K_{d}\right)\right) \\
& =\frac{\sigma \bar{\Phi}_{e}}{\sigma-1}\left(M_{e}\left(\underline{\mathrm{x}}_{e}\right) / \delta-C_{d}-C_{e}\right)-\left(1+i \tau_{d}\right) M_{e}^{d}\left(\underline{\mathrm{x}}_{e}\right)-\left(1+i \tau_{e}\right) M_{e}^{e}\left(\underline{\mathrm{x}}_{e}\right) \\
& -\frac{\sigma \bar{\Phi}_{d}}{\sigma-1}\left(M_{d}\left(\underline{\mathrm{x}}_{e}\right) / \delta-C_{d}\right)+\left(1+i \tau_{d}\right) M_{d}\left(\underline{\mathrm{x}}_{e}\right)-\frac{(1-\delta)}{\delta}\left(M_{e}\left(\underline{\mathrm{x}}_{e}\right)-M_{d}\left(\underline{\mathrm{x}}_{e}\right)\right) \\
& =\left(\frac{\sigma \bar{\Phi}_{e}}{\sigma-1}-1-i \delta\left(\tau_{d} \eta_{d}+\tau_{e} \eta_{e}\right)\right)\left(M_{e}\left(\underline{\mathrm{x}}_{e}\right) / \delta-C_{d}-C_{e}\right)-\left(1+i \delta \tau_{e}\right) C_{e} \\
& -\left(\frac{\sigma \bar{\Phi}_{d}}{\sigma-1}-1-i \delta \tau_{d}\right)\left(\frac{\bar{\Phi}_{d}}{\bar{\Phi}_{e}}\right)^{-\sigma} \eta_{d}\left(M_{e}\left(\underline{\mathrm{x}}_{e}\right) / \delta-C_{d}-C_{e}\right) .
\end{aligned}
$$

Putting these together, we can solve out the loans for the cutoff exporter as, using the same trick as in $(54)$,

$$
\begin{aligned}
& M_{e}\left(\underline{\mathrm{x}}_{e}\right) / \delta-C_{d}-C_{e} \\
& =\frac{\left(1+i \delta \tau_{e}\right) C_{e}}{\left(\frac{\sigma \bar{\Phi}_{e}}{\sigma-1}-1-\frac{\bar{\Phi}_{e}}{\theta}-i \delta\left(\tau_{d} \eta_{d}+\tau_{e} \eta_{e}\right)\right)-\left(\frac{\sigma \bar{\Phi}_{d}}{\sigma-1}-1-\frac{\bar{\Phi}_{d}}{\theta}-i \delta \tau_{d}\right)\left(\frac{\bar{\Phi}_{d}}{\bar{\Phi}_{e}}\right)^{-\sigma} \eta_{d}} \\
& =\frac{(\sigma-1)\left(1+i \delta \tau_{e}\right) C_{e}}{\left(1+i \delta\left(\tau_{d} \eta_{d}+i \tau_{e} \eta_{e}\right)\right)-\left(1+i \delta \tau_{d}\right)\left(\frac{\bar{\Phi}_{d}}{\bar{\Phi}_{e}}\right)^{-\sigma} \eta_{d}} \\
& =\frac{1+i \delta \tau_{e}}{\left(1+i \delta\left(\tau_{d} \eta_{d}+i \tau_{e} \eta_{e}\right)\left(1-\left(\frac{1+i \delta\left(\tau_{d} \eta_{d}+\tau_{e} \eta_{e}\right)}{1+i \delta \tau_{d}}\right)^{\sigma-1} \eta_{d}\right)\right.}(\sigma-1) C_{e} \\
& =\Delta(\sigma-1) C_{e},
\end{aligned}
$$


where $\Delta$ is defined as in the text. We then have the loan for the cutoff exporter as,

$$
M_{e}\left(\underline{\mathrm{x}}_{e}\right)=(\Delta(\sigma-1)+1) C_{e}+C_{d} .
$$

Substituting the solution of the loan for the cutoff exporter into (52), and with rather extensive simplification, we can solve for the interest payment for the cutoff exporter as shown in (27). Notice that the parameter $\Theta$ is derived by

$$
\begin{aligned}
\Theta & =\rho_{e} I_{e}\left(\underline{\mathrm{x}}_{e}\right)-\left[\bar{\Phi}_{e}+\delta\left(1-\rho_{e}\right)-1\right] M_{e}\left(\underline{\mathrm{x}}_{e}\right) / \delta \\
& =\bar{\Phi}_{e} C_{e}\left(\left(1-\left(\frac{\bar{\Phi}_{e}}{\bar{\Phi}_{d}}\right)^{\sigma-1} \eta_{d}\right) \Delta-1\right)-\left(\bar{\Phi}_{e}-\bar{\Phi}_{d}\right) C_{d}-\left(1-\rho_{e}\right) K_{e} \\
& =\bar{\Phi}_{e} C_{e}\left(\frac{1+i \delta \tau_{e}}{1+i \delta\left(\tau_{d} \eta_{d}+\tau_{e} \eta_{e}\right)}-1\right)-\left(\bar{\Phi}_{e}-\bar{\Phi}_{d}\right) C_{d}-\left(1-\rho_{e}\right) K_{e} \\
& =\frac{i \delta\left(\tau_{e}-\tau_{d}\right)}{\left(1-\frac{\sigma-1}{\sigma \theta}\right)}\left(\eta_{d} C_{e}-\eta_{e} C_{d}\right)-\left(1-\rho_{e}\right) K_{e}
\end{aligned}
$$

where the first equality follows by substituting in the expected interest payment by the cutoff exporter (52), the expected interest payment by domestic firms (56) and the loan for the cutoff exporter, and the second equality holds by substituting in $\Delta$.

If the cash-flow constraint is binding for the cutoff exporter $\underline{x}_{e}$ but not the cutoff domestic firm $\underline{\mathrm{x}}_{d}$ in the above solution, then we substitute (55) into (52) and simplify to obtain,

$$
\begin{aligned}
\rho_{e} I_{e}\left(\underline{\mathrm{x}}_{e}\right) & =\left[\bar{\Phi}_{e}+\delta\left(1-\rho_{e}\right)-1\right] \frac{M_{e}\left(\underline{\mathrm{x}}_{e}\right)}{\delta}-\left(1-\rho_{e}\right) K_{e}+\frac{\bar{\Phi}_{e}}{(\sigma-1)} \frac{M_{e}\left(\underline{\mathrm{x}}_{e}\right)}{\delta} \\
& -\frac{\bar{\Phi}_{d}}{(\sigma-1)} \frac{M_{d}\left(\underline{\mathrm{x}}_{e}\right)}{\delta}+\frac{\sigma \bar{\Phi}_{d}}{\sigma-1} C_{d}-\frac{\sigma \bar{\Phi}_{e}}{\sigma-1}\left(C_{d}+C_{e}\right) .
\end{aligned}
$$

This level of interest payments ensures that $E\left(\pi_{e}\left(\underline{\mathrm{x}}_{e}, \underline{\mathrm{x}}_{e}\right)\right)=E\left(\pi_{d}\left(\underline{\mathrm{x}}_{e}, \underline{\mathrm{x}}_{e}\right)\right)$. Accordingly, the bank can choose the minimum $\underline{x}_{e}$ at which the cash flow constraint of the exporter is satisfied, and then set the interest payments as in (58) to ensure this equality of profits for the cutoff exporter.

\section{A.3 Monotonicity of Profits}

It is readily shown that profits are increasing in $x$ :

$$
\begin{aligned}
\frac{d E\left(\pi_{d}(x, x)\right)}{d x} & =\left(\frac{\sigma}{\sigma-1} \bar{\Phi}_{d}+\delta\left(1-\rho_{d}\right)-1\right) \frac{M_{d}^{\prime}(x)}{\delta}-\rho_{d} I_{d}^{\prime}(x) \\
& =\left(\frac{\sigma}{\sigma-1} \bar{\Phi}_{d}+\delta\left(1-\rho_{d}\right)-1\right) \frac{M_{d}^{\prime}(x)}{\delta}-\left[\bar{\Phi}_{d}+\delta\left(1-\rho_{d}\right)-1\right] \frac{M_{d}^{\prime}(x)}{\delta} \\
& =\frac{\bar{\Phi}_{d}}{\sigma-1} \frac{M_{d}^{\prime}(x)}{\delta}>0 .
\end{aligned}
$$

where the second line follows from the incentive-compatibility condition (6). Similarly, we can establish that the profits of the exporter are also increasing: $\frac{d E\left(\pi_{e}(x, x)\right)}{d x}=\frac{\bar{\Phi}_{e}}{\sigma-1} \frac{M_{e}^{\prime}(x)}{\delta}>0$. Substituting from the loans schedules in $(20)$, it can be shown that $\left(\frac{\left(1+\left(\tau_{d} \eta_{d}+\tau_{e} \eta_{e}\right) i \delta\right)}{\left(1+i \delta \tau_{d}\right)}\right)^{\sigma-1} \eta_{d}<1$ is needed to ensure that $d E\left(\pi_{e}(x, x)\right) / d x>d E\left(\pi_{d}(x, x)\right) / d x$. 